\title{
A LA BÚSQUEDA DE LA IDENTIDAD CONSTITUCIONAL: \\ UNA APROXIMACIÓN AL CASO ESPAÑOL Y EUROPEO EN CLAVE DE PLURALISMO CONSTITUCIONAL Y DIÁLOGO JUDICIAL
}

\author{
MÓNICA MARTÍNEZ LÓPEZ-SÁEZ
}


SUMARIO

1. CONSIDERACIONES PRELIMINARES Y CLARIDAD CONCEPTUAL: LA NATURALEZA DE LA UE Y LA NOCIÓN DE «IDENTIDAD CONSTITUCIONAL» EN EL CONTEXTO DE LA INTEGRACIÓN EUROPEA; 1.1. La naturaleza de la UE, la integración europea y los desafíos en clave judicial, 1.2. La identidad constitucional como concepto indeterminado; 2. MÉTODOS DE IDENTIFICACIÓN DE LA IDENTIDAD CONSTITUCIONAL Y SU CONCRETA PLASMACIÓN EN ESPAÑA; 2.1. Los preámbulos constitucionales, 2.2. La jerarquía de disposiciones constitucionales, 2.3. Las cláusulas de eternidad, 2.4. Los requisitos de afiliación, 2.5. La interpretación constitucional; 3. ANÁLISIS DE LA «IDENTIDAD NACIONAL DE LOS ESTADOS MIEMBROS» A LA LUZ DEL ENTRAMADO NORMATIVO-JURISPRUDENCIAL Y SU PAPEL EN LA APLICACIÓN DE LA PRIMACÍA DEL DERECHO DE LA UE; 3.1. La materialización de la identidad constitucional en la UE, 3.2. La evolución de la identidad constitucional como contralímite a la primacía del Derecho de la UE; 4. ARRIESGADO ACERCAMIENTO ALTERNATIVO A LA IDENTIDAD CONSTITUCIONAL EUROPEA: MÁS ALLÁ DE LAS «TRADICIONES CONSTITUCIONALES COMUNES»; 5. CONSIDERACIONES FINALES SOBRE IDENTIDADES CONSTITUCIONALES DIVERGENTES: DIÁLOGO JUDICIAL CONSTRUCTIVO COMO PREVALENTE SOLUCIÓN A LA TENSIÓN DIALÉCTICA ENTRE PRIMACÍA EUROPEA VERSUS RESPETO DE LAS IDENTIDADES NACIONALES. 


\title{
A LA BÚSQUEDA DE LA IDENTIDAD CONSTITUCIONAL: UNA APROXIMACIÓN AL CASO ESPAÑOL Y EUROPEO EN CLAVE DE PLURALISMO CONSTITUCIONAL Y DIÁLOGO JUDICIAL ${ }^{1}$
}

\author{
MÓNICA MARTÍNEZ LÓPEZ-SÁEZ²
}

\author{
1. CONSIDERACIONES PRELIMINARES Y CLARIDAD \\ CONCEPTUAL: LA NATURALEZA DE LA UE Y LA NOCIÓN \\ DE IDENTIDAD CONSTITUCIONAL» EN EL CONTEXTO \\ DE LA INTEGRACIÓN EUROPEA
}

\subsection{La naturaleza de la UE, la integración europea y los desafíos en clave constitucional}

Uno de los fenómenos más singulares y relevantes en el ámbito histórico, político y, sobre todo, jurídico-constitucional, que se ha desarrollado en la Europa posterior a la Segunda Guerra Mundial es, sin duda, el proceso de integración europeo. Naturalmente, si bien es verdad que la dualidad de este concepto lo hace difícilmente comprensible (pues puede definirse como el proceso de unión y como cualquier etapa

${ }^{1}$ El presente trabajo se ha elaborado en el marco de la «Red temática en justicia constitucional y diálogo judicial» (acrónimo: JUDICO) financiada por el MINECO (Acciones de dinamización «Redes de excelencia», referencia DER2016-81801-REDT), cuyo investigador principal es el Dr. Luis Ignacio Gordillo Pérez y en el marco del Grupo de Investigación sobre Derechos Humanos y Carta Social Europea (GIUV2013-148) cuya directora es Carmen Salcedo Beltrán.

${ }^{2}$ Investigadora Predoctoral (FPU) en Derecho Constitucional de la Universidad de Valencia (Estudio General). Máster en Estudios Internacionales y de la Unión Europea (2016, UVEG) y Máster en Traducción Institucional (Jurídico-Económica) (2016, Universitat d'Alacant). Departamento de Derecho Constitucional y Ciencia Política Facultad de Derecho - Universitat de València Av. Los Naranjos, s/n - 46022 Valencia Email: Monica.Martinez-Lopez@uv.es 
determinada de este proceso $^{3}$ ), no es menos cierto que su concepción como modelo ha sido intensamente argüida por gran parte de la doctrina académica: de tal suerte, son tres las teorías clásicas de integración, a saber, la soberanía compartida (MacCormick), el contractualismo federal (Weiler) y la gobernanza multinivel (Marks y Hooghe ${ }^{4}$ ), respectivamente. Y curiosamente, en el contexto de la Unión Europea, el Diccionario Oxford sobre Historia Mundial Contemporánea define la integración como aquella formación de estados europeos y como la asociación regional más unida del mundo, que ha asumido considerables características propias de una entidad estatal.

Como es sabido, la Unión Europea («UE», en adelante), tomando en consideración su configuración y corpus normativo constitutivo, como fuentes emanantes de la misma, se rigió, en sus orígenes, por el Derecho Internacional, creándose en un principio como una suerte de organización internacional en la que estados soberanos europeos se asociaban para alcanzar una serie de objetivos comunes y asegurar, así, la paz en el continente. Ello se ve reflejado en la terminología empleada en el artículo 1 del Tratado de la Unión Europea: «Por el presente Tratado, las Altas Partes Contratantes constituyen entre sí una Unión Europea». No obstante, si observamos la estructura y la naturaleza jurídico-política de la UE, esta se presenta un tanto más constitucional: los tratados constitutivos, a saber, el Tratado de la Unión Europea (TUE), el Tratado de Funcionamiento (TFUE) y la Carta de Derechos Fundamentales de la Unión Europea (CDFUE), a partir de la reforma del Tratado de Lisboa, muestran elementos propios de un texto constitucional, reflejados tanto en "partes orgánicas» (regulando los distintos poderes y estableciendo el marco institucional y decisorio) como «dogmáticas» (consagrando principios rectores así como derechos y libertades fundamentales) ${ }^{5}$.

Obviamente, también cabe destacar que la UE constituye una unión de estados soberanos a la que estos, sobre la base del principio de atribución de competencias, ceden parte de su soberanía (o, a tenor de la célebre fórmula utilizada en el clásico caso Costa/ENEL, «una limitación definitiva de su soberanía» $)^{6}$ para alcanzar dichos objetivos comunes, negando así su naturaleza de organización internacional. Este desposeimiento del poder soberano de los Estados miembros a la propia UE, adquiriendo ésta competencias propias, aunque en ocasiones limitadas, también pone de

3 MILCZAREK, D.: «Genesis of the United Europe. From the Roman Empire to the European Union», en MILCZAREK, D., ADAMCZYK, A., y ZAJACZKOWSKI, K. (Eds.) Introduction to European studies. A new approach to uniting Europe, Centrum for Europe University Warsaw, Varsovia, 2001, p. 58.

${ }^{4}$ HOOGHE, L., y MARKS, G. Multi-Level Governance and European Integration Rowman \& Littlefield -Governance in Europe Series, Lanham, 2001.

5 Para un análisis sobre cuestiones relativas a la integración europea y los derechos fundamentales emergentes, véase MARTÍNEZ LÓPEZ-SAÉZ, M.: «Hacia una integración digital europea: la constitucionalización del derecho de la UE y la europeización del Derecho Constitucional en materia de protección de datos», Revista de Estudios Europeos, n. ${ }^{\circ} 71$ (enero-junio), 2018, p. 24.

${ }^{6}$ Sentencia del Tribunal de Justicia de 15 de julio de 1964 (asunto 6/64). 
manifiesto su inadmisibilidad como estado. La UE, a pesar de su vocación federal ${ }^{7}$, no se puede considerar una entidad estatal pues carece de una serie de elementos definitorios de un Estado, entre ellas la falta de plena soberanía ${ }^{8}$. La Unión Europea no goza de soberanía sino que el origen de sus limitados poderes se hace a través de la soberanía estatal de Estados ya constituidos y reconocidos por el Derecho Internacional. En otras palabras, la UE sólo dispone de competencias de atribución (art. 5.2 TUE), no disponiendo de poderes generales sino de aquellos poderes concretados en los Tratados constitutivos?.

Desde estas dos ópticas, la UE se constituye como una situación jurídica intermedia sin precedentes; un híbrido entre estado nacional y organización internacional. De ahí, precisamente deriva su consideración sui generis y su clasificación de organización «supranacional» ${ }^{10}$. La integración europea, como consecuencia de un proceso de más de medio siglo, sigue siendo la única instancia en la historia humana donde encontramos un grupo regional profundamente unificado, basado en sus propias premisas ideológico-políticas específicas, comúnmente llamadas valores y objetivos comunes. En efecto, es el experimento más exitoso hasta la fecha de gobernanza supranacional con el objetivo originario de garantizar el mantenimiento de la paz en Europa y proteger los derechos humanos. Aun así, este ha supuesto la existencia de un ordenamiento jurídico supranacional y otros veintiocho ordenamientos jurídicos nacionales que operan simultáneamente, a pesar de la diversidad

7 La Unión Europea, tal y como se visionó y se ha articulado a través de las décadas, se inspira y se vertebra sobre valores y principios federalistas. Así lo exponen Jimena Quesada y Tajadura «La Unión Europea presenta numerosos rasgos propios de un esquema federal de articulación del poder: las instituciones comunitarias ejercen directamente potestades normativas y jurisdiccionales sobre los particulares; existe un orden de distribución de competencias entre la Unión y los Estados miembros; los mecanismos de resolución de conflictos encajan también en el esquema federal». Véase JIMENA QUESADA. L., y TAJADURA TEJADA, J.: «La prehistoria y la historia del derecho constitucional europeo (ensayo de paralelismo con el decurso del derecho constitucional nacional)», Revista de Derecho Político n. ${ }^{\circ}$ 94, (septiembre-diciembre), 2015, pp. 30-31.

${ }^{8}$ No obstante, lo que no se puede negar, es que la UE, al igual que un Estado soberano, es sujeto de Derecho Internacional pues puede ser destinatario de normas que atribuyen derechos y obligaciones internacionales. De manera generalizada, se le ha reconocido a la UE como una Organización Internacional (aunque no una clásica sino de integración) puesto que deriva de un acto fundacional concertado voluntariamente por los EM. Y, de todos modos, no cabe olvidar que, con la entrada en vigor del Tratado de Lisboa, la UE adquirió personalidad jurídica, y en consecuencia, pasó a ser un sujeto del Derecho Internacional, con la potestad para negociar y celebrar acuerdos internacionales en su propio nombre. Véase, en este sentido, GOSALBO BONO, R.: «Insuficiencias jurídicas e institucionales de la acción exterior de la Unión Europea», Revista de Derecho Comunitario Europeo, n. ${ }^{\circ} 50$ (enero/abril), 2015, pp. 231-320.

9 MANGAS MARTÍN, A.: «La distribución de competencias en la Unión Europea y el principio de subsidiariedad», Fundación Manuel Giménez Abad de Estudios Parlamentarios y del Estado Autonómico, Parlamento de Navarra, 2008, p. 2.

10 Sobre dicha clasificación, léase TORRES DEL MORAL, A.: «El Estado supranacional e inter-

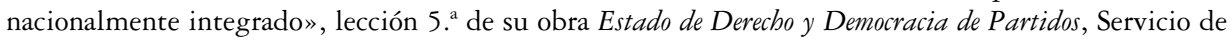
Publicaciones de la Facultad de Derecho de la Universidad Complutense, Madrid, 3. a ed., 2010.

N.o 105, mayo-agosto 2019, págs 315-358 
y peculiaridades de estructuras y entramados jurídicos entre todos ellos. Desde esta perspectiva, la diversidad constitucional no es solo una evidencia empírica, sino la premisa normativa del proceso de integración europea, en general, y el reflejo de su pluralismo constitucional amparado en el lema «unidad en la diversidad», en particular. Desde luego, la integración europea se ha basado, en su nivel más básico, en la aceptación y confianza mutua entre Estados y en la aceptación de un ordenamiento supranacional con vistas a proteger unos valores compartidos y alcanzar unos objetivos comunes.

Resulta difícil imaginar, que cuando los estados soberanos europeos se unieron al proyecto europeo, no fueron capaces de percibir los efectos que dicha integración tendría sobre sus propios ordenamientos jurídicos, transformando sus concepciones tradicionales sobre la soberanía, la democracia y el Estado de Derecho, y por tanto, sus estructuras político-constitucionales. De hecho, tal y como observa Claes, las propias constituciones nacionales han divisado, de manera explícita o implícita, «cláusulas europeas» o de «habilitación» al permitir la transferencia de competencias a entidades u organizaciones supraestatales ${ }^{11}$. Por todo lo anterior, la pluralidad constitucional también implica la existencia de ordenamientos, convergentes a la vez que autónomos, con pretensiones encontradas sobre quién posee la autoridad definitiva. Se plantea, ante esta situación jurídica única, cómo habilitar la aplicación efectiva del Derecho de la UE en el plano nacional y hasta qué punto un ordenamiento constitucional autónomo puede aceptar limitaciones a su soberanía provenientes de fuentes externas a su sistema, rompiendo con su propia «cadena de mando» constitucional $^{12}$. Así, se entiende por qué, en los últimos años, la diversidad constitucional, esta vez en forma de identidad constitucional, se ha convertido en un concepto frecuentemente invocado y apelado en los discursos jurídico-constitucionales y populares del ámbito europeo, generando fricciones allá donde se invoca. Iglesia Chamarro nos recuerda que «emerge, así, una noción bisagra en la articulación compleja entre el Derecho del Estado y el de la Unión Europea, o si se quiere, entre la noción de supremacía y la primacía del Derecho comunitario» ${ }^{13}$, todo lo cual analizaremos con detenimiento en las páginas siguientes.

La relación entre la justicia constitucional y el proceso de integración europea nos traslada, como consecuencia jurídica natural, a los desafíos a los que se enfrenta este

${ }^{11}$ Así lo examina detalladamente CLAES, M.: «Constitutionalizing Europe at its Source: The «European Clauses» in the National Constitutions: Evolution and Typology», Oxford Yearbook European Law, Vol. 24, 2005, pp. 81-125; así como POPELIER, P.: «Europe Clauses» and Constitutional Strategies in the Face of Multi-Level Governance», Maastricht journal of European and comparative law (The Constitutional Adulthood of Multi-Level Governance), Vol. 21, n. ${ }^{\circ} 2,2014$, pp. 305-310.

12 POPELIER, P.: «Europe Clauses» and Constitutional Strategies in the Face of Multi-Level Governance...op. cit., p. 303.

13 DE LA IGLESIA CHAMARRO, A.: «La identidad constitucional como barrera y garantía para la supervivencia de los Estados constitucionales», ponencia en la Jornada internacional sobre "La Constitución como pacto», celebrada el 23 de marzo de 2018 en la Facultad de Derecho de la Universidad de Valencia. 
proceso. Ello es así porque los tribunales constitucionales desarrollan sus funciones en relación con un cuerpo jurídico autónomo e independiente que tienen que interpretar, aplicar y salvaguardar, a saber, su ordenamiento, que, aunque distinto, está innegablemente vinculado al europeo. Por ese motivo, la relación entre el ordenamiento europeo y los ordenamientos nacionales se articula principalmente mediante la relación entre el Tribunal de Justicia de la Unión Europea («TJUE», en adelante) y los tribunales constitucionales de los Estados miembros. La naturaleza sui generis de la UE, así como la supuesta inexistencia de una constitución europea, o mejor dicho, la ausencia de un contexto «constitucional pleno» ${ }^{14}$, hace que el Tribunal de Justicia tenga que realizar funciones incomparables, hasta el punto que haya establecido principios fundamentales y rectores de la relación entre el ordenamiento europeo y los ordenamientos nacionales, teniendo como resultado, en ocasiones, la inaplicación o reconsideración de multitud de normas, principios y derechos nacionales, a veces incluso constitucionales, a favor de las europeas. Sin embargo, no se puede olvidar que la integración constitucional en la UE, o lo que ya llamó Cruz Villalón la constitucionalización de Europa ${ }^{15}$, se ha realizado en gran parte desde los ordenamientos constitucionales nacionales. He ahí el énfasis en las «tradiciones constitucionales comunes» de los Estados miembros, reflejado tanto en los tratados constitutivos, mediante remisión genérica al Derecho constitucional de los Estados miembros como mecanismo de integración y parámetro interpretativo en el artículo 6.3 del Tratado de la Unión Europea («TUE», en adelante) ${ }^{16}$, en el preámbulo ${ }^{17}$ y en el artículo 52.4 de la Carta de Derecho Fundamentales de la UE («CDFUE», en adelante), así como

${ }^{14}$ Pues, como argumentaremos más adelante, a nuestro modo de ver, el hecho de que el sistema normativo de la UE no se lidere por un texto constitucional per se no significa que no exista una constitución europea. Es evidente que no cabe atribuir la naturaleza de «Estado constitucional» a dicha organización supranacional ni el carácter de «Constitución formal» a su Derecho primario (del que forma parte, por lo demás, la CDFUE tras la vigencia del Tratado de Lisboa en diciembre de 2009), pese a lo cual es común (y en tal línea se inscribe el presente trabajo) referirse a lo que Bar Cendón ya llamó «Constitución europea material». Véase BAR CENDÓN, A.: «La Constitución de la Unión Europea: contexto, reforma y virtualidad», Revista Valencia d'Estudis Autonòmics (Ejemplar dedicado a Europa en la

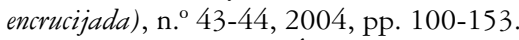

${ }^{15}$ CRUZ VILLALÓN, P.: «La Constitución inédita. La dificultad del debate constitucional europeo», Revista Española de Derecho Europeo, n. ${ }^{\circ}$ 1, 2002, pp. 9-29.

16 «Los derechos fundamentales que garantiza el Convenio Europeo para la Protección de los Derechos Humanos y de las Libertades Fundamentales y los que son fruto de las tradiciones constitucionales comunes a los Estados miembros formarán parte del Derecho de la Unión como principios generales».

17 «La Unión contribuye a defender y fomentar estos valores comunes dentro del respeto de la diversidad de culturas y tradiciones de los pueblos de Europa, así como de la identidad nacional de los Estados miembros (...) La presente Carta reafirma, dentro del respeto de las competencias y misiones de la Unión, así como del principio de subsidiariedad, los derechos que emanan, en particular, de las tradiciones constitucionales y las obligaciones internacionales comunes a los Estados miembros, del Convenio Europeo para la Protección de los Derechos Humanos y de las Libertades Fundamentales, las Cartas Sociales adoptadas por la Unión y por el Consejo de Europa, así como de la jurisprudencia del Tribunal de Justicia de la Unión Europea y del Tribunal Europeo de Derechos Humanos» 
en más de dos centenares de pronunciamientos del TJUE ${ }^{18}$ a lo largo de su historia jurisdiccional.

Pues bien, es precisamente en este sentido, que hemos podido observar los intentos controvertidos de varios tribunales constitucionales nacionales de desafiar abiertamente la primacía del Derecho de la UE y la autoridad del Tribunal de Justicia de la UE en pronunciamientos recientes, invocando su tradición constitucional como suprema a través de la noción de la identidad nacional para justificar el incumplimiento de normas, principios y derechos consagrados en la $\mathrm{UE}^{19}$. No obstante, antes de entrar en el estado de la cuestión de la identidad constitucional nacional dentro del contexto de la UE, resulta necesario ofrecer algunas aclaraciones conceptuales.

\subsection{La identidad constitucional como concepto indeterminado}

El concepto de «identidad constitucional» ha recibido mucha atención por la doctrina académica en años recientes ${ }^{20}$; ahora bien, resulta todavía difícil tratar de

${ }^{18}$ Búsqueda rápida con los siguientes criterios seleccionados: Tribunal $=$ «Tribunal de Justicia, Tribunal General», Documentos = Documentos publicados en la Recopilación: Sentencias - Dictámenes - Opiniones

Palabras del texto $=$ «tradiciones constitucionales comunes». Todo ello disponible en: http://curia. europa.eu/juris/documents. jsf? pro $=\&$ nat $=$ or $\&$ oqp $=\& l g=\&$ dates $=\&$ language $=$ es $\&$ jur $=\mathrm{C} \% 2 \mathrm{CT} \& \mathrm{cit}=-$ none $\% 252 \mathrm{CC} \% 252 \mathrm{CCJ} \% 252 \mathrm{CR} \% 252 \mathrm{C} 2008 \mathrm{E} \% 252 \mathrm{C} \% 252 \mathrm{C} \% 252 \mathrm{C} \% 252 \mathrm{C} \% 252 \mathrm{C} \% 252 \mathrm{C} \% 252 \mathrm{C}$ $\% 252 \mathrm{C} \% 252 \mathrm{C} \% 252 \mathrm{Ctrue} \% 252 \mathrm{Cfalse} \% 252 \mathrm{Cfalse} \& \mathrm{td}=\% 3 \mathrm{~B} \% 3 \mathrm{~B} \% 3 \mathrm{BPUB} 1 \% 2 \mathrm{CPU}-$ $\mathrm{B} 4 \% 2 \mathrm{CPUB} 8 \% 3 \mathrm{~B} \% 3 \mathrm{~B} \% 3 \mathrm{BORDALL} \& \mathrm{text}=\% 2522$ tradiciones $\% 2 \mathrm{~B}$ constitucionales $\% 2 \mathrm{Bcomu}-$ nes $\% 2522 \&$ pcs $=$ Oor\&avg $=\&$ page $=1 \&$ mat $=$ or $\&$ jge $=\&$ for $=\& c i d=85527$

19 Podemos poner, como ejemplos recientes, los siguientes. En primer lugar, el Tribunal Constitucional checo, en su sentencia de 2012 declaró un acto europeo ultra vires, y por tanto, determinó su invalidez en el territorio checo. En segundo lugar, el Tribunal Supremo de Dinamarca, que, en su sentencia de 2016, tras una cuestión prejudicial al Tribunal de Justicia de la UE, determinó la imposibilidad de aplicar el Derecho de la UE por excederse en las competencias que Dinamarca había transferido a la UE en su tratado de adhesión. En tercer lugar, el Tribunal Constitucional húngaro, en su sentencia 22/2016, decidió que, en situaciones excepcionales, es competente para decidir si aplica o no el Derecho de la UE cuando entra en colisión con los derechos fundamentales o la identidad soberana húngara consagradas en su texto constitucional. Para un análisis detallado de estas decisiones judiciales, véase KÜHN, Z.: «Ultra Vires Review and the Demise of Constitutional Pluralism. The Czecho-Slovak Pension Saga, and the Dangers of State Courts' Defiance of EU Law», Maastricht journal of European and Comparative Law, Vol. 23, n. ${ }^{\circ}$ 1, pp. 185-194; RASK MADSEN, M., PALMER OLSEN, H., y SADL, U.: «Competing Supremacies and Clashing Institutional Rationalities: The Danish Supreme Court's Decision in the Ajos Case and the National Limits of Judicial Cooperation», University of Copenhagen Faculty of Law Legal Studies Research Paper Series, n. ${ }^{\circ} 32$, 2017, pp. 1-16; y MOHAY, A. y TÓTH, N. «Decision 22/2016. (XII. 5.) AB on the Interpretation of Article E)(2) of the Fundamental Law» American Journal of International Law, Vol. 111, n. ${ }^{\circ} 2$, 2017, pp. 468-475, respectivamente.

${ }^{20}$ ROSENFELD, M.: The Identity of the Constitutional Subject: selfhood, culture, and community, Routledge, 2010; JACOBSOHN, G.: Constitutional identity, 2010. Concretamente, en lo que a la Unión Europea se refiere, véase también SAIZ ARNAIZ, A., y ALCOBERRO ILIVINA, C.: National Constitutional Identity and European Integration, Intersentia-Law and Cosmopolitan Values, Cambridge, Vol. 4, 
definir la noción enigmática de «identidad constitucional» y su ámbito de aplicación, pues encontramos nociones y concepciones filosóficas y sociológicas similares a la par que diferentes tales como el caractère national de Rousseau, el génie d»une nation de Montesquieu, el Volksgeist de Hegel, el constitutional essentialism de Rawls y la constitutional identity de Smith; todo ello, sin acometer la tipificación de las nociones de identidad social, identidad colectiva, identidad política, sensibilidad nacional o identidad nacional. Para todas ellas cabría hablar no sólo de la identificación (¿Quiénes somos como comunidad organizada?) sino también de afiliación y pertenencia (¿Qué nos une?). Además, al igual que la identidad personal, para un colectivo particular (sea una comunidad o una nación) el «quién soy» o «qué me hace peculiarmente yo» es una pregunta relativa, y más práctica que teórica ${ }^{21}$ : podemos ser fruto de una serie de características físico-objetivas, psíquico-subjetivas (miedos, aspiraciones, valores) y podemos ser fruto de los roles que desempeñamos.

Lo innegable es que, tanto las personas como las naciones, somos fruto de una construcción histórico-socio-cultural concreta y, en definitiva, somos fruto de un contexto y un contenido particular y, por ende, peculiar y distintivo. Sin embargo, no se debe confundir la identidad o sensibilidad nacional con la identidad constitucional. La necesidad de una identidad colectiva o nacional, así como su convergencia y divergencia con respecto a la noción de identidad constitucional son fáciles de aprehender, si entendemos la importancia de un «vínculo social» y los beneficios de una «cohesión comunitaria» o de una «estabilidad social» en un ordenamiento determinado ${ }^{22}$, lo que se traslada igualmente al terreno constitucional. En efecto, las personas y la ciudadanía, en general, necesitan un núcleo mínimo de elementos y valores comunes compartidos que les permite relacionarse entre sí y que proporcionan un sentimiento de pertenencia.

Por lo tanto, de forma paralela, cabe afirmar que el concepto de «identidad constitucional» carece de una definición general aceptada. Se podría considerar como categoría derivada de la identidad nacional ${ }^{23}$, o aparejarla al concepto de «tradición constitucional», aunque esta concepción, como bien apunta parte de la doctrina, debe entenderse en sentido amplio, considerándose no sólo algo que pertenece al pasado sino también como algo que pervive jurídicamente en el presente ${ }^{24}$, en tanto en cuanto

2013; y MILLET, F.X.: L'Union européenne et l'identité constitutionnelle des États membres, L.G.D.J- Bibliothèque constitutionnelle et de science politique, Paris, 2013.

${ }^{21}$ VON BOGDANDY, A.: «Identidad Constitucional. Exploración de un fenómeno ambiguo con ocasión de la política de identidad europea de lege lata y lege ferenda», Revista Española de Derecho Constitucional, n. ${ }^{0} 75$ (septiembre-diciembre), 2005, p. 17.

22 ORGAD, L.: The Cultural Defense of Nations: A Liberal Theory of Majority Rights, Oxford University Press, 2016, pp. 206-207.

${ }^{23}$ CRUZ VILLALÓN, P.: «La identidad constitucional de los Estados miembros: dos relatos europeos», Anuario de la Facultad de Derecho de la Universidad Autónoma de Madrid, n. ${ }^{\circ}$ 17, 2013, p. 501.

${ }^{24}$ SADURSKI, W: «European Constitutional Identity», Sydney Law School Research Paper No. 06/37, 2006, p. 6. 
realiza una linking function ${ }^{25}$. Otros autores consideran que esta podría concebirse como el núcleo y conjunto de valores y principios fundamentales que no pueden verse comprometidos a cualquier precio ${ }^{26}$ o como aquella que protege las peculiares características de una constitución y lo que hace idiosincrático a un orden constitucional concreto. También es verdad que existe una parte de la doctrina que clasifica este concepto jurídico no sólo como un principio del Derecho de la UE y fundamento de su integración, sino también como un concepto intrínsecamente político ${ }^{27}$ que no únicamente deriva de un «pseudo-derecho constitucional» ${ }^{28}$. Todo ello, a su vez, hace necesario explorar el concepto de «constitución» y los diferentes enfoques que ella nos puede proporcionar a la hora de definir una identidad constitucional concreta.

\section{MÉTODOS DE IDENTIFICACIÓN DE LA IDENTIDAD CONSTITUCIONAL Y SU CONCRETA PLASMACIÓN EN ESPAÑA}

Así pues, en lo que a métodos para la identificación de la identidad constitucional se refiere, tal y como indican Jacobsohn ${ }^{29}$ o Von Bogdandy ${ }^{30}$, la propia Constitución es un buen punto de partida. La constitución cuenta una historia constitucional mediante partes informativas (quiénes somos como comunidad política constitucionalmente organizada, de dónde venimos, hacia dónde queremos ir y por qué) y normativas (qué queremos enfatizar en la organización de nuestra comunidad política y cómo queremos enfatizarlo). En efecto, la existencia de un texto constitucional y el contenido o disposiciones del mismo, cabalmente pueden mostrar elementos distintivos o un contexto sociocultural concreto en el cual opera dicha constitución. El contexto es, sin duda, significativo, si tenemos en cuenta los diferentes modelos constitucionales y procesos constituyentes, ya que explican las circunstancias sociales, culturales e históricas determinadas que llevaron a una redacción muy particular, a un contenido constitutivo específico y, potencialmente, a identificar una identidad constitucional concreta. Es por ello que resulta necesario analizar ciertos elementos presentes en la constitución, como documento jurídico supremo de un estado, adoptado por el poder constituyente, que consagra los principios y valores rectores del

25 BELOV, M.: «The Functions of Constitutional Identity Performed in the Context of Constitutionalization of the EU Order and Europeanization of the Legal Orders of EU Member States», Perspectives on Federalism, Vol. 9, n. ${ }^{\circ}$ 2, 2017, pp. 87-88.

${ }^{26}$ JACOBSOHN, G.: «Constitutional Values and Principles», en ROSENFELD, M., y SAJÓ, A.: Oxford Handbook of Comparative Constitutional Law, Oxford University Press, Oxford, 2010, p. 777.

27 MENÉNDEZ-MENÉNDEZ, A.J.: «Una concepción alternativa de la identidad constitucional en el Derecho comunitario: de las excepciones idiosincráticas a la resistencia constitucional colectiva», Anuario de la Facultad de Derecho de la Universidad Autónoma de Madrid, n. ${ }^{\circ}$ 17, 2013, p. 577.

${ }_{28}$ MENÉNDEZ-MENÉNDEZ, A.J.: «Una concepción alternativa...op. cit., p. 580.

29 JACOBSOHN, G.: «The formation of constitutional identities», en Comparative Constitutional Law, Edward Elgar Publishing, 2011, p. 131.

30 VON BOGDANDY, A.: «Identidad Constitucional... Op. cit., p. 30. 
ordenamiento jurídico, establece y organiza los poderes estatales así como las estructuras políticas y jurídicas y protege los derechos y libertades fundamentales de sus ciudadanos. Por este motivo, un análisis más detallado del preámbulo de una constitución, de la existencia de una jerarquía de fuentes así como de la existencia de límites materiales y formales o prohibiciones absolutas a enmiendas constitucionales, son elementos a tener en cuenta a la hora de fundamentar la existencia o el mantenimiento de una identidad constitucional ${ }^{31}$, los cuales se analizarán a continuación.

\subsection{Los preámbulos constitucionales}

En primer lugar, cabe analizar el preámbulo de una constitución como instrumento de identificación de la identidad constitucional. Sin entrar en la discusión doctrinal del valor jurídico de los preámbulos constitucionales ${ }^{32}$, examinar el preámbulo de cualquier constitución permite apuntar las peculiaridades y atipicidades que caracteriza un proceso constituyente concreto. El «de dónde venimos», «hacia dónde queremos ir», «lo que valoramos» y por qué son elementos comunes presentes en los preámbulos de las constituciones del mundo. El modelo constitucional español es exclusivo de un Estado que, después de un régimen autoritario, quiso aspirar a un Estado social y democrático basado en el Estado de Derecho y cumplir los requisitos políticos, económicos-sociales y jurídicos para poder afiliarse al club europeo y separarse del régimen anterior, pero que también tenía que encontrar el difícil equilibrio entre la unidad nacional y la «autonomía» regional para apaciguar a los diferentes grupos «subnacionales». Este objetivo se logró a través de negociaciones entre los líderes del régimen anterior y los partidarios de un nuevo orden constitucional -lo que se ha acuñado como el «Modelo de Transición Pactado» ${ }^{33}$.

Todo lo cual se ve claramente consagrado en el Preámbulo de la Magna Carta española: «La Nación española, deseando establecer la justicia, la libertad y la seguridad y promover el bien de cuantos la integran, en uso de su soberanía, proclama su voluntad de: Garantizar la convivencia democrática dentro de la Constitución y de las leyes conforme a un orden económico y social justo. Consolidar un Estado de Derecho que asegure el imperio de la ley como expresión de la voluntad popular. Proteger a todos los españoles y pueblos de España en el ejercicio de los derechos bumanos, sus culturas y tradiciones, lenguas e instituciones. Promover el progreso de la cultura y de la economía para asegurar a todos una digna calidad de vida. Establecer una sociedad democrática avanzada, y Colaborar en el fortalecimiento de unas relaciones pacíficas y de eficaz cooperación entre todos los pueblos de la Tierra [énfasis nuestro]».

31 También propone los suyos GREWE, C.: «Methods of identification of National Constitutional Identity», en SAIZ ARNAIZ, A., y ALCOBERRO ILIVINA, C. (eds) National Constitutional Identity and European Integration, Intersentia-Law and Cosmopolitan Values, Cambridge, Vol. 4, 2013, pp. 37-48.

32 Por todos, la obra de TAJADURA TEJADA, J.: El Preámbulo Constitucional, Granada, Comares, 1997.

33 ROSENFELD, M: «Constitutional Identity», en ROSENFELD, M., y SAJO, A., (eds.) The Oxford Handbook of Comparative Constitutional Law, Oxford University Press, Oxford, 2012, p. 769. 
Aunque el preámbulo de la Constitución Española no hace referencia, de manera explícita a una narrativa o testimonio histórico del pueblo español y del proceso constituyente español, los principios, valores y objetivos fundamentales que su preámbulo formula, como expresión de aquello que el orden constitucional español quiere enfatizar como esencial y como característico, como alusiones implícitas a la historia y peculiaridades de la misma y a las aspiraciones que el pueblo español quiere destacar, con base en ella, podrían considerarse perfectamente parte de la identidad constitucional de España. En efecto, el énfasis puesto en la «Nación española», los «españoles»y los «pueblos de España» «culturas»y «lenguas» muestra, precisamente, ese intento de equilibrio entre la soberanía nacional y la autonomía regional. Y, por ejemplo, el acento en asegurar la «paz», la convivencia «pacífica», la «cooperación», y la «libertad»y «seguridad» muestra el necesario distanciamiento de la guerra civil y la dictadura franquista. Del mismo modo, la recurrente alusión a un estado «democrático», «de Derecho» que protege los «derechos humanos» y la «dignidad humana» muestra las aspiraciones de cumplir con las exigencias políticas del proceso europeo.

\subsection{La jerarquía de disposiciones constitucionales}

En segundo lugar, otro método de identificación de la identidad constitucional consistiría en encontrar una jerarquía de normas, valores, derechos o principios consagrados explícita o implícitamente en la constitución. No causa extrañeza, por ello mismo, la particularidad de que la Constitución Alemana de 1949 dedicara su primer capítulo precisamente a la consagración y protección de los derechos fundamentales, incluyendo, curiosamente, la dignidad humana como «sagrada» y primero de ellos ${ }^{34}$. La reforma llevada a cabo en 1990 de la Constitución Alemana no cambió la posición de este artículo o el orden en el que se consagra la dignidad humana dentro del ordenamiento constitucional alemán, aunque sí se reformuló de la siguiente manera: «La dignidad es intangible. Respetarla y protegerla es obligación de todo poder público». Todo lo cual hace incuestionable que la noción de dignidad humana, dada también su historia tan particular en el último siglo, tiene un status especial en el ordenamiento constitucional alemán ${ }^{35}$, y por ende, podría constituir (como de hecho se ha visto que

\footnotetext{
${ }^{4}$ No obstante, no es hasta 1958 que el Tribunal Constitucional Federal alemán otorga oficialmente a los derechos fundamentales un carácter de proposición fundamental suprema de su ordenamiento democrático, materializado bajo el principio de la Dignidad humana como valor supremo del ordenamiento constitucional bajo una obligación de respeto hacia el ser humano. Para un resumen y análisis del caso Mephisto, véase VON MUNCH, I.: «La dignidad del hombre en el Derecho Constitucional», Revista Española de Derecho Constitucional, n. ${ }^{\circ}$, 1989, pp. 9 y ss.

35 Para un análisis exhaustivo de los modelos de recepción constitucional de la dignidad humana, tanto con enfoque comparado como teniendo en cuenta los parámetros internacionales europeos al respecto, véase OEHLING DE LOS REYES, A.: La dignidad de la persona. Evolución histórico-filosófica, concepto, recepción constitucional y relación con los valores y derechos fundamentales, Madrid, Dykinson, Madrid, 2010; para el acercamiento concreto a esa posición de la dignidad asentada en la Grundgesetz, véanse pp. 246 a 266.
} 
constituye según la doctrina jurisprudencial alemana y europea) parte de su identidad constitucional $^{36}$.

En el caso de España podríamos argumentar que la ubicación de una norma, principio, valor, institución o derecho en particular dentro de nuestra Carta Magna determina su prevalencia jerárquica, o en otras palabras, cabría esgrimir que aquellos valores, principios, instituciones, normas o derechos que gozan de especial protección legislativa (con una reserva de ley) y/o judicial (con una tutela jurisdiccional reforzada) son jerárquicamente superiores a otros elementos previstos en la constitución. Este sería el caso, por ejemplo, de los artículos 14 a 29 y 30.2 de la Constitución española, que consagran derechos y libertades fundamentales, ya que no sólo requieren, simplificando y a grandes rasgos, de un procedimiento legislativo especial a través de la ley orgánica como única norma apta para desarrollarlos ${ }^{37}$, sino que también son derechos cuya invocación abre un vía procesal singular ante un órgano jurisdiccional excepcional, como es el Tribunal Constitucional, a través del archiconocido recurso de amparo ${ }^{38}$. Como es sabido, esa opción del constituyente, de la que parte de la doctrina ha derivado semejante jerarquización, vinculada a dicha idea restrictiva de fundamentalidad, no es objeto de unanimidad, máxime cuando se tienen presentes los estándares internacionales sobre derechos humanos (y la idea de indivisibilidad) o los textos más recientes del constitucionalismo comparado (especialmente en América Latina).

\subsection{Las cláusulas de eternidad}

En tercer lugar, otro método relevante de identificación de la identidad constitucional sería analizar la existencia y el contenido de las llamadas cláusulas de eternidad $o$ de intangibilidad (unamendability clauses, en inglés ${ }^{39}$ ) como límites formales-procesales y/o materiales-sustanciales para la revisión constitucional, y por tanto como una forma de proteger los valores y principios fundamentales y esenciales que se consideran inmutables; en breve, examinar la existencia y contenido de los límites, cuando no prohibiciones, a cierta reforma constitucional. La idea misma de que un ordena-

36 Véase, por todos, el asunto C-36/02, Omega, STJUE de 14 de octubre de 2004.

37 La Constitución ha establecido en su artículo 81 una reserva especial, que se orienta al desarrollo de los derechos fundamentales y las libertades públicas: «Son leyes orgánicas las relativas al desarrollo de los derechos fundamentales y de las libertades públicas, las que aprueben los Estatutos de Autonomía y el régimen electoral general y las demás previstas en la Constitución. 2. La aprobación, modificación o derogación de las leyes orgánicas exigirá mayoría absoluta del Congreso, en una votación final sobre el conjunto del proyecto».

38 Véase artículo 53.2 CE: "Cualquier ciudadano podrá recabar la tutela de las libertades y derechos reconocidos en el artículo 14 y la Sección 1. ' del Capítulo Segundo ante los Tribunales ordinarios por un procedimiento basado en los principios de preferencia y sumariedad y, en su caso, a través del recurso de amparo ante el Tribunal Constitucional. Este último recurso será aplicable a la objeción de conciencia reconocida en el artículo 30».

39 ROZNAI, Y.: «Unamendability and the Genetic Code of the Constitution», New York University Public Law and Legal Theory Working Papers, Paper 514, 2015, p. 10. Otra noción equivalente ha sido el concepto brasileño de «cláusula pétrea» en HÜBNER MENDES, C.: «Judicial Review of Constitutional Amendments in the Brazilian Supreme Court» Florida Journal of International Law, Vol. 17, 2005, pp. 449-452. 
miento jurídico tenga un procedimiento de enmienda o reforma constitucional que permita la corrección de errores, la subsanación de carencias o la consagración de conceptos y elementos formados a lo largo del tiempo, sea a través de la práctica o de experiencias imprevistas, es relativamente razonable. Los textos constitucionales deberían poder modificarse, siempre y cuando dicha modificación se plantee mediante un procedimiento, constitucionalmente previsto, de enmienda: un procedimiento de reforma (o revisión) constitucional. Un procedimiento de reforma constitucional se establece como principio esencial respecto del «mantenimiento» de la Constitución escrita: «a bealing principle that would allow a constitution to stand the test of time» ${ }^{40}$.

No obstante, se puede argumentar que, con el fin de garantizar suficiente seguridad y estabilidad jurídica, no debería ser excesivamente fácil modificar la constitución, por un lado, aunque, también se puede argumentar que las llamadas cláusulas de eternidad ${ }^{41}$ son cuestionables en la medida que «entorpecen el discurso de la constitucionalidad» ${ }^{42}$ al impedir una reconsideración de dicho texto, como la materialización jurídica del sentimiento de nacionalidad de un pueblo, así como de su visión común en un momento particular de la historia ${ }^{43}$, por otro. Efectivamente, las cláusulas de eternidad como regla general dotan de estabilidad a la sociedad (que por definición es dinámica y está expuesta a cambios constantes) y al ordenamiento jurídico. Sin embargo, también se debe argumentar que ciertos valores, principios y elementos esenciales necesitan protección especial y los mecanismos para garantizar dicha protección pueden implicar el diseño, si no de cláusulas de eternidad, al menos de límites o restricciones a un posible poder de enmienda. Una forma de limitar el supracitado poder de enmienda se puede justificar, precisamente, desde la citada perspectiva de la jerarquía de valores, derechos o principios explícita o implícitamente consagrados en la constitución, así como a través de un posible procedimiento de reforma constitucional.

En efecto, a fin de proteger los derechos inviolables de las personas, los principios y los valores esenciales y característicos de un estado constitucional, puede ser imprescindible articular un cierto control a la reforma constitucional, especialmente en aquellos órdenes constitucionales que surgieron de circunstancias específicas que dieron lugar precisamente a la violación de dichos derechos o valores, y que, por lo tanto, son susceptibles de incorporar ese tipo de particularidades o refuerzos constitucionales justamente para salvaguardarlos. Y, ciertamente, una forma de limitar el poder de modificación antes mencionado puede verse desde la óptica de

40 ROZNAI, Y. : Unconstitutional Constitutional Amendments. The Limits of Amendment Powers, Oxford University Press 2017, p. 3.

41 Algunos autores, como Balaguer Callejón, también las han calificado de «previsiones constitucionales expresas encadenadas a disposiciones intangibles» (véase BALAGUER CALLEJÓN, F.: «Los tribunales constitucionales en el proceso de integración europea», Revista Española de Derecho Constitucional Europeo, núm. 7, 2007, p. 357).

42 ROZNAI, Y.: Unconstitutional Constitutional Amendments. The Limits of Amendment Powers, Oxford University Press, Oxford, 2017, pp. 4-5.

43 HALMAI, G.: "Judicial Review of Constitutional Amendments and New Constitutions in Comparative Perspective» Wake Forest Law Review, Vol. 13, n. ${ }^{\circ} .38,2016$, p. 104. 
un procedimiento de revisión constitucional «duro», siendo especialmente interesante en el caso de España ${ }^{44}$.

Desde la experiencia constitucional española existen dos procedimientos de revisión o reforma constitucional para enmendar su Carta Magna, establecidos en su Título X: una revisión parcial ordinaria y una revisión parcial agravada o total de la Constitución. Ambos procedimientos confirman la posibilidad de enmendar la Constitución, pero también muestran la rigidez del procedimiento de revisión constitucional. El segundo procedimiento, el llamado procedimiento agravado ${ }^{45}$, además de corroborar la rigidez del procedimiento de enmienda constitucional, también demuestra la naturaleza inmutable de ciertos principios y derechos consagrados en la Constitución española. Estos, de acuerdo con el artículo 168.1, son aquellos recogidos en el «Título Preliminar, al Capítulo Segundo, Sección 1. a del Título I, o al Título II». En principio, esto incluiría no sólo los derechos y libertades fundamentales consagrados en los artículos 14 a 29 y $30.2^{46}$ de la Constitución española que, curiosamente, como ya se ha señalado, son aquellos que requieren una redacción y desarrollo a través de una ley orgánica y gozan de una protección reforzada mediante el recurso de amparo, en caso de presunta vulneración (Capítulo Segundo, Sección 1. a del Título I), sino también principios, valores y estructuras político-constitucionales esenciales y peculiares a España como son la forma política consagrada en una monarquía parlamentaria, la unidad del territorio español, el pluralismo político, el respeto a la Constitución por parte de los poderes públicos, el estado de las autonomías ${ }^{47}$, entre muchas otras

${ }^{44}$ Que se sitúa en el contexto del post-franquismo con el «Modelo Transicional Pactado» antes mencionado, dando como resultado el Modelo Constitucional Español particular, que establece un marco para un Estado multiétnico o multinacional con diferentes sensibilidades y conducente a una constitucionalización del Derecho Internacional y Europeo, entre otras razones, con la finalidad de alejarse del pasado y ser capaz de unirse al proyecto de construcción europeo.

${ }_{45}$ El procedimiento agravado supone un proceso de cuatro pasos: (1) La reforma propuesta será aprobada por una mayoría de dos tercios de los miembros de cada Cámara (tanto del Congreso de los Diputados como del Senado); (2) El Parlamento español (ambas cámaras) se disolverá; (3) El Parlamento recién elegido deberá ratificar la decisión y proceder a examinar el nuevo texto constitucional, que deberá aprobarse, una vez más, por una mayoría de dos tercios de los miembros de cada Cámara; (4) y una vez aprobado a nivel legislativo, se someterá a ratificación por referéndum.

46 Consagrando derechos fundamentales, como el derecho a la vida, a la libertad religiosa, a la libertad de expresión, al derecho de información, al derecho de asociación, a aquellos derechos personalísimos o aquellos relativos a las garantías judiciales, entre otros muchos.

${ }^{47} \mathrm{Y}$ esta es precisamente la razón por la cual también haría necesario aludir a la cuestión de las autonomías en relación con la cuestión catalana, pues he aquí donde podemos observar la estrecha relación entre las cláusulas de eternidad (o de otro tipo de cláusulas limitadoras de enmienda constitucional) y el concepto de identidad constitucional en tanto en cuanto tratan de proteger ciertos valores (ya sean universales o particulares a la constitución e identidad de ese estado). El debate interno sobre la identidad constitucional en España se ha reducido principalmente a la llamada «cuestión territorial» y los acontecimientos actuales han dado más visibilidad a una controversia que se viene desarrollando en España desde la aprobación de nuestra Constitución. En el caso de España, no obstante, podría argumentarse jurídicamente que, además de la protección de los derechos y principios fundamentales, la organización territorial, como parte de esas estructuras constitucionales básicas tan particular y la transferencia 
(artículos 1 a 9 que constituyen parte del Título Preliminar) y la regulación y funciones de la Corona española (artículos 56 a 65 del Titulo II).

Por lo tanto, aunque no existe una jerarquía explícita de normas o derechos en la Constitución española, vemos cómo ciertos derechos, principios y estructuras políticas gozan de una protección reforzada y están sujetos a un procedimiento de enmienda que, aunque de iure no impide su replanteamiento o revisión constitucional, de facto la hace más difícil, aunque no imposible, si se alcanza la mayoría cualificada en los procesos de votación y demás requisitos establecidos en el artículo 168 (entre ellos, el referéndum). En otras palabras, la adopción de un procedimiento de enmienda constitucional especial se establece, en el ordenamiento constitucional español, como un principio rector general y funcional con respecto al mantenimiento de nuestra Constitución escrita ${ }^{48}$, y como un principio instrumental con respecto a la protección de los principios, derechos fundamentales y estructuras políticas esenciales consagradas en el ordenamiento constitucional. Es decir, la Constitución española, a través de su versión light de cláusulas de eternidad, parece considerar este procedimiento de revisión constitucional agravado como el «guardián de la Constitución y sus principios más esenciales» ${ }^{49}$, o, dicho en otros términos, como el guardián de lo que podría considerarse el «núcleo» de la identidad constitucional española.

\subsection{Los requisitos de afiliación}

Al margen de lo anterior, también podemos encontrar rastros de identidad constitucional fuera de un texto constitucional. Así, en cuarto lugar, habría que hacer alusión a lo que se ha decidido llamar requisitos esenciales de afiliación o los criterios esenciales de adhesión, y que otros autores ya han estudiado como cultural defence $^{50} \mathrm{o}$ "conversión cívica» ${ }^{51}$. En términos — todos ellos— poco sencillos, hacen alusión a los requisitos mínimos imperativos necesarios para aceptar a nuevos miembros a una comunidad o estado; o sea, los elementos inherentes al estado que deben ser conocidos

de «poderes» o competencias otorgadas a las Comunidades Autónomas en temas específicos, tratando de conciliar la unidad de la nación española y las culturas socio-históricas de las regiones (art. 2 CE), permitiendo el autogobierno y algún nivel de desarrollo legislativo en el ámbito regional, es también un elemento particular o distintivo de la identidad constitucional española. En este sentido, véase MARTÍNEZ LÓPEZ-SAÉZ, M.: «¿Existe una identidad constitucional en España?», Comunicación presentada en la Jornada internacional sobre «La Constitución como pacto», celebrada el 23 de marzo de 2018 en la Facultad de Derecho de la Universidad de Valencia.

48 También es interesante mencionar que el artículo 169 actúa como una excepción y un límite absoluto del procedimiento de revisión constitucional en tiempos de guerra, en estados de alarma, de emergencia o de sitio, lo que también muestra la importancia de mantener y preservar la Constitución, especialmente en situaciones de «crisis», asegurando y conservando el orden establecido.

${ }^{49}$ BONFIGLIO, S.: Constitucionalismo mestizo. Más allá del colonialismo de los Derechos Humanos, Tirant lo Blanch, Valencia, 2017, pp. 55-61.

${ }^{50}$ ORGAD, L.: The Cultural Defense of Nations... op. cit. pp. 158-159.

${ }^{51}$ ORGAD, L.: The Cultural Defense of Nations... op. cit. pp. 203-204. 
y aceptados por los recién llegados para obtener la nacionalidad. No debe olvidarse que esto ya lo apuntaba Rousseau al hablar de una religión civil: «hay pues una profesión de fe puramente civil (...) pertenece al Soberano fijar, no precisamente como dogmas de religión, sino como sentimientos de sociabilidad sin los que es imposible ser un buen ciudadano y fiel vasallo» ${ }^{52}$. Este vínculo y consenso común que une a los ciudadanos y que se les exige a los aspirantes a la ciudadanía pueden reflejar los valores, principios y elementos básicos, esenciales y particulares de esa sociedad o comunidad política y, por tanto, constituiría ese núcleo mínimo de apego socio-constitucional al que, de alguna manera u otra, hacía alusión Rousseau.

De hecho, en numerosos países del mundo, a los solicitantes de nacionalidad se les exige que conozcan, se ajusten y proclamen los pilares y elementos fundamentales de ese estado, para así poder adaptarse mejor y formar parte de ese vínculo común. En el proceso de naturalización estadounidense, por ejemplo, entre los requisitos se incluye poder leer, escribir y hablar inglés básico, una comprensión básica de la historia y el gobierno de los Estados Unidos (civics), y además, según la vigente Ley de Inmigración y Nacionalidad de 1952, se exige demostrar una buena conducta y, por lo que nos interesa "demonstrate an attachment to the principles and ideals of the U.S. Constitution and a favorable disposition to the United States» (simpatizar y respetar los principios e ideales consagrados en la Constitución estadounidense y una actitud positiva hacia el estado constitucional americano $)^{53}$. De manera similar, en el proceso de naturalización español, uno de los documentos que debe acompañar el correspondiente formulario de solicitud es un certificado de aprovechamiento de la «prueba de conocimientos constitucionales y socioculturales de España» («CCSE», por sus siglas en castellano), que evalúa precisamente, a través de diferentes pruebas, el conocimiento del solicitante de la Constitución ( los derechos y deberes de los españoles, el marco institucional y organización territorial, leyes fundamentales), la historia, cultura y sociedad española, así como comportamientos y valores socialmente aceptados en España ${ }^{54}$. En principio, por lo tanto, se podría identificar la identidad constitucional de un estado concreto observando qué valores, principios, derechos y estructuras políticas considera tan esenciales que su conocimiento, aceptación o simpatía son exigidos a aquellos que quieren, formal y jurídicamente, adherirse o ser ciudadano del mismo.

52 ROUSSEAU, J.J: El contrato social, 1819, Libro IV, Capítulo VIII.

53 La primera ley estadounidense que regulaba el proceso de naturalización, fue la Ley de Nacionalidad de 1790 que restringía la ciudadanía a cualquier extranjero libre y blanco, residente en EE. UU. durante dos años y que podía demostrar un buen carácter moral, y prestar juramento y apoyo hacia la Constitución. En su última versión modificada, la Ley de Inmigración y Nacionalidad de 1952 (INA) exige, entre otros requisitos, que el solicitante sea de buen carácter moral y que tenga un «apego a los principios de la Constitución». En el acto regulador que lo acompaña (INA Sec. 316. [8 U.S.C. 1427) se especifican los requisitos de "Residence, Good Moral Character, Attachment to the Principles of the Constitution, and Favorable Disposition to the United States». Disponible en: https://www.uscis.gov/ilink/docView/SLB/HTML/SLB/act.html

54 Para más información, véase https://examenes.cervantes.es/es/ccse/como 


\subsection{La interpretación constitucional}

Por último, cabría intentar identificar qué constituye la identidad constitucional de un estado examinando la interpretación judicial que el intérprete constitucional supremo de ese estado considera que debe entenderse por tal. Nuevamente, aproximándonos al caso español, cabe señalar los siguientes aspectos interesantes. El Tribunal Constitucional español solo ha hecho referencia a la noción de «identidad constitucional» como tal tres veces en su larga historia. Así, a pesar de que no nos interese la interpretación pretendida tanto en la STC 95/1996, de 21 de junio, como en la STC 203/2015 de 5 de octubre, sobre cuestiones de derecho laboral relacionadas con sindicatos, comités de empresa y delegados de personal, utilizó el término como sinónimo de base jurídico-constitucional, o en otras palabras, como algo expresamente reconocido en la Constitución ${ }^{55}$, sí que resulta de nuestro interés la primera referencia a la identidad constitucional como parte esencial de la tradición constitucional española de la que se sirvió nuestro Tribunal Constitucional en la STC 26/2014 de 13 de febrero.

Conviene comenzar recordando que esta sentencia contiene el fallo del famoso asunto Melloni, cuyo fallo sólo fue posible tras la remisión de la primera cuestión prejudicial de nuestro garante supremo al TJUE en el marco de un recurso de amparo contra la resolución de 12 de septiembre de 2008 de la Sala de lo Penal de la Audiencia Nacional española, a través de la cual se emitió la orden de detención de un ciudadano italiano en el marco de la ejecución de una orden de detención europea formulada por un juez italiano para cumplir una condena penal por un delito de quiebra fraudulenta. El TC utiliza este mecanismo europeo por primera vez, planteando una cuestión prejudicial al TJUE, teniendo en cuenta tanto la legislación de la UE, su doctrina constitucional así como su propia relación con el TJUE en el marco del dialogo entre tribunales en el contexto de integración europea ${ }^{56}$. A lo largo

55 Véase por ambas, el fundamento jurídico quinto de la sentencia más reciente: «Lo anterior no conduce a eliminar por completo las diferencias subsistentes entre los sindicatos, de un lado, y los comités de empresa y delegados de personal, por otro, ya que, de una parte, no existe una identidad constitucional entre aquéllos y éstos (STC 118/1983, de 13 de diciembre, FJ 4) y, de otra, los órganos unitarios no tienen constitucionalmente garantizada la libertad sindical consagrada en el art. 28.1 CE (por todas, STC 134/1994, de 9 de mayo, FJ 4). Pero esa circunstancia no oculta que, en el supuesto de becho examinado, el recurrente en amparo, miembro del comité de empresa, estaba afiliado a la CGT y era secretario de su sección sindical, de suerte que la actividad desplegada en funciones de representación como miembro del comité no podia desvincularse de la sindicalización que definía su perfil distintivo. En ello abunda que tal condición la invocara la propia empresa en los documentos antes citados, o que la sanción precedente a la que se refería el comunicado publicado y controvertido, en tanto que afectaba a dicho representante (sindicalizado), dotara a los avatares procesales de aquélla de interés sindical para los empleados cuyos derechos laborales el recurrente sancionado estaba llamado a defender.» [énfasis nuestro].

56 Sobre esta y otras cuestiones sobre el dialogo judicial en el marco del constitucionalismo multinivel europeo, véanse, entre otros, VIDAL PRADO, C.: El impacto del nuevo Derecho europeo en los Tribunales constitucionales, Colex, Madrid, 2004; TORRES DEL MORAL, A.: «Relaciones entre la Unión Europea y los Estados miembros según el Tratado Constitucional Europeo: principios que las rigen», 
de la sentencia, observamos la referencia constante a que la primacía del Derecho de la Unión Europea opera sobre la base del respeto de los valores y tradiciones constitucionales comunes y, concretamente en su fundamento jurídico tercero, hace referencia al «respeto de las estructuras constitucionales básicas nacionales entre las que se encuentran los derechos fundamentales» y que «la Constitución no es ya el marco de validez de las normas comunitarias (...) si bien la Constitución exige que el Ordenamiento aceptado como consecuencia de la cesión sea compatible con sus principios y valores básicos». Acaba, además, concluyendo que el Tribunal Constitucional deberá concretar qué valores, intereses y estructuras esenciales, que acuña «exigencias más básicas o elementales» como aquellas que componen su identidad constitucional.

A partir de tan escueta proclamación, cabe también destacar las referencias a la identidad constitucional española comentada por los magistrados en sus votos particulares concurrentes. La Magistrada Adela Asua Batarrita recuerda las consecuencias interpretativas de la famosa DTC 1/2004, que analizaremos seguidamente: «se dirigen a subrayar los límites de la integración europea. La aceptación de la primacía del Derecho de la Unión está condicionada — se reitera hasta tres veces con distintas formulaciones-al respeto de los principios y valores básicos de la Constitución " ${ }^{57}$. De modo similar, la Magistrada Encarnación Roca Trías nos proporciona una acercamiento a la noción de identidad constitucional: "no obstante, que si bien dichos limites (...) que "implícitamente se derivan de la Constitución y del sentido esencial del propio precepto" y que "se traducen en el respeto de la soberanía del Estado, de nuestras estructuras constitucionales básicas y del sistema de valores y principios fundamentales consagrados en nuestra Constitución, en el que los derechos fundamentales adquieren sustantividad propia (art. $10.1 \mathrm{CE}$ )" ${ }^{58}$. Y por último, y de nuevo, en términos idénticos, el Magistrado Andrés Ollero Tassara nos vuelve a recordar que «la cesión constitucional que el art. 93 CE posibilita tiene a su vez límites materiales no recogidos expresamente en el precepto constitucional, pero que implícitamente se derivan de la Constitución y del sentido esencial del propio precepto, se traducen en el respeto de la soberanía del Estado, de nuestras estructuras constitucionales básicas y del sistema valores y principios fun-

Revista de Derecho Político n. ${ }^{\circ}$ 65, 2006, pp. 91-114; TENORIO SÁNCHEZ, P.: «Tribunal Constitucional y cuestión prejudicial ante el Tribunal de Justicia de la Unión Europea», Diario La Ley n. . 7520 , 2010, pp. 1-5; D’ATENA, A.: La constitución oculta de Europa (antes y después de Lisboa), ReDCE, Año 7, n. ${ }^{\circ} 13$ (enero-junio), 2010. pp. 17-46; AGUILAR CALAHORRO, A.: «La primera cuestión prejudicial planteada por el Tribunal Constitucional al Tribunal de Justicia de la Unión Europea (Auto del TC 86/2011, de 9 de junio)», Revista de Derecho Constitucional Europeo n. . 16, 2011; JIMENA QUESADA, L.: Jurisdicción nacional y control de convencionalidad: A propósito del diálogo judicial global y de la tutela multinivel de derechos, Thomson Reuters Aranzadi, Pamplona, 2013, pp. 23-52; GORDILLO PÉREZ, L.I., y MARTINICO, G.: Historias del país de las hadas. La jurisprudencia constitucionalizadora del Tribunal de Justicia, Civitas/Thomson Reuters (Cuadernos Civitas), Madrid, 2015; JIMENA QUESADA, L.: «La cuestión prejudicial europea ante planteamientos más que dudosos», Teoría y Realidad Constitucional, n. ${ }^{\circ}$ 39, 2017, pp. 270-306.

57 STC 26/2014 de 13 de febrero (p. 96 BOE). disponible en: http://hj.tribunalconstitucional.es/ docs/BOE/BOE-A-2014-2650.pdf

58 Id. $\mathrm{BOE}$ (p. 101). 
damentales consagrados en nuestra Constitución, en el que los derechos fundamentales adquieren sustantividad propia (...) la Constitución exige que el Ordenamiento aceptado como consecuencia de la cesión sea compatible con sus principios y valores básicost.... $» 59$.

En apunte similar, el Tribunal Constitucional español ha hecho referencia a su identidad «nacional» dos veces en su historia jurisprudencial. La primera ocasión, ya citada anteriormente, se dio con la Declaración 1/2004, de 13 de diciembre, sobre la existencia o no de contradicción entre la Constitución española y el Tratado por el que se creaba una Constitución para la UE, afirmando que, en lo relativo al «respeto de la identidad nacional de los Estados miembros» como consideración necesaria a la aplicación del Derecho de la UE, en ningún caso, podría verse anulada incluso a pesar de la transferencia de determinadas competencias a la UE y que esta «identidad nacional» viene «a consagrar la garantía de la existencia de los Estados y sus estructuras básicas, así como sus valores, principios y derechos fundamentales». Y, además, el Tribunal Constitucional recuerda que «los limites a que se referían las reservas de [ciertas] jurisdicciones constitucionales [que condujo a un necesario dialogo entre tribunales nacionales y el TJUE mediante el procedimiento de cuestión prejudicial culminando en hitos jurisprudenciales europeos] aparecen abora proclamados de modo inequívoco por el propio Tratado sometido a nuestra consideración, que ha venido a acomodar sus disposiciones a las exigencias de las Constituciones de los Estados miembros (...) se construye sobre (...) tradiciones constitucionales» ${ }^{60}$.

A raíz de las últimas decisiones del garante supremo de nuestra Constitución, vemos cómo se ha acogido al argumento de identidad «constitucional»o «nacional» como reducto de la potestad originaria de los Estados, entendiéndose ellos mismos como señores o dueños de los tratados, y como fundamento para la reivindicación de una supuesta competencia exclusiva jurisdiccional ${ }^{61}$. Por último, y aunque como mera referencia sin desarrollar, y con la honesta intención de ser exhaustivos en la búsqueda, cabe aludir a que el Tribunal Constitucional español volvió a citar la noción de identidad nacional en sus SSTC 42/2014 y 114/2017 sobre la inconstitucionalidad de la declaración de soberanía de Cataluña, y la convocatoria unilateral de un referéndum sobre su independencia por oponerse a los principios constitucionales básicos que reconocen la unidad de la nación española y del pueblo español; aunque en ambas ocasiones, su utilización ha sido de mera remisión a la disposición vigente en el Tratado de la Unión Europea (artículo 4.2, que analizaremos más adelante).

El Tribunal Constitucional español, por tanto, ha arrojado poca pero interesante luz en lo que constituye la identidad constitucional española, ya que, por un lado, ha ofrecido criterios para su determinación, pero, por otro, no ha visto la necesidad de profundizar por ahora en la cuestión. Sin embargo, como se ha puesto de manifiesto, tenemos a nuestro alcance instrumentos normativos y herramientas interpretativas para determinar la identidad constitucional.

\footnotetext{
59 Id. BOE (p. 105).

60 Véase FJ3 DTC 1/2004.

61 CRUZ VILLALÓN, P.: «La identidad constitucional de los Estados...op. cit. p. 507.
} 


\section{ANÁLISIS DE LA «IDENTIDAD NACIONAL DE LOS ESTADOS MIEMBROS»A LA LUZ DEL ENTRAMADO NORMATIVO- JURISPRUDENCIAL Y SU PAPEL EN LA APLICACIÓN DE LA PRIMACÍA DEL DERECHO DE LA UE}

\subsection{La materialización de la identidad constitucional en la UE}

La noción de identidad constitucional, en su fórmula de «identidad nacional»se convirtió oficialmente en derecho constitutivo de la UE con la reforma del Tratado de Maastricht, que incluía en la primera sección de su artículo F la siguiente declaración: "La Unión respetará la identidad nacional de sus Estados miembros, cuyos sistemas de gobierno se basarán en los principios democráticos». Es interesante mencionar que con esta reforma del año 92 se consagraron otra serie de nociones y aspectos básicos de una integración europea más político-jurídica, impulsada por fuerzas supranacionales, como la regulación de una «unión» europea o la positivización de una «ciudadanía» europea $^{62}$, dotada de derechos y obligaciones (véase, por ejemplo, su artículo 8), pero también encontramos fuerzas intergubernamentales en juego para contrarrestar la constitucionalización de Europa, limitándola, entre otras, con la obligación de respetar esas identidades nacionales. Este contralímite ${ }^{63}$ consagrado en el Derecho de la UE es un reflejo de la intención decidida de los Estados miembros, de conformidad con el principio de atribución de poderes, para afirmarse como actores políticos relevantes y soberanos en los procesos políticos y jurídicos europeos. En efecto, como apunta Cruz Villalón, "La Unión y su ciudadanía debian nacer con un enérgico recordatorio de la autonomía —en el sentido fuerte de la expresión — de las unidades politicas prexistente integrantes de la Unión» ${ }^{64}$, pero conviene, sin embargo, advertir que precisamente el Tratado de Maastricht habla del respeto hacia las identidades nacionales de los Estados (que no de su soberanía), mostrando, en realidad, el calado de lo que llevaba recorrido ya el proceso de integración europeo.

${ }^{62}$ En efecto, los avances del proyecto de construcción europeo, en torno a la noción de ciudadanía europea, sea por su consagración en el Tratado de Maastricht de 1992, sea por los elementos novedosos propugnados por el fallido Tratado constitucional de 2004, sea por su consagración y «rescate sustancial» por el Tratado de Lisboa de 2007, han sido todos intentos de crear un ius commune europeo con el objetivo de acentuar una unidad política y sentimiento de pertenencia.

63 Véase por todos: MARTINICO, G.: «Complexity and Cultural Sources of Law in the EU Context: From the Multilevel Constitutionalism to the Constitutional Synallagma», German Law Journal, Vol. 8, n. ${ }^{\circ}$ 3, 2007, pp. 205-230; CELOTTO, A.: «Derecho UE y derecho nacional: primauté vs contralímites», en Gómez Fernández, I. (Coord), CARTABIA, M., DE WITTE, B., y PÉREZ TREMPS, P. (dirs) Constitución europea y constituciones nacionales, Tirant lo Blanch, Valencia, 2005, pp. 287-372; VECCHIO, F.: «Primacía del derecho europeo y salvaguarda de las identidades: consecuencias asímetricas de la europeización de los contralimites», Agencia Estatal Boletín Oficial del Estado, Madrid, 2015.

${ }^{64}$ CRUZ VILLALÓN, P.: «La identidad constitucional de los Estados...op. cit. p. 503. 
Saltándonos algunas etapas del proyecto de integración europeo, y a pesar del fallido tratado constitucional de 2004, es preciso aludir a él, y sobremanera a su artículo I-5, pues el contenido relativo a la identidad nacional de los Estados miembros parece haberse traspasado si no textual, desde luego fielmente, al texto de la reforma del Tratado de Lisboa de 2007, enunciando, en su artículo 4.2 TUE, no precisamente de manera sucinta, lo siguiente: «La Unión respetará la igualdad de los Estados miembros ante los Tratados, así como su identidad nacional, inberente a las estructuras fundamentales políticas y constitucionales de éstos, también en lo referente a la autonomía local y regional. Respetará las funciones esenciales del Estado, especialmente las que tienen por objeto garantizar su integridad territorial, mantener el orden público y salvaguardar la seguridad nacional» [énfasis nuestro].

En el contexto de la UE, la identidad nacional también es un concepto jurídico ambiguo e indefinido. Por un lado, la identidad nacional no necesariamente tiene que coincidir con la identidad estatal en sentido estricto; algunos Estados miembros son multinacionales y muchos son históricamente o están actualmente compuestos por minorías étnicas y lingüísticas. Por otro lado, resulta que las identidades culturales lingüísticas, étnicas, religiosas, históricas o sociales, ya están reconocidas y protegidas por otras disposiciones del derecho primario de la $U^{65}$. Todo lo cual podría indicar que la «identidad nacional» no se debe interpretar principalmente en un sentido cultural-histórico. Precisamente del énfasis recalcado anteriormente parece más coherente que el respeto de la «identidad nacional», en el contexto europeo, se equiparase al respeto de aquellos elementos políticos y constitucionales esenciales y particulares de cada Estado miembro, o en otras palabras, a aquellos aspectos inherentes y esenciales de sus órdenes constitucionales, aludiendo, más bien a dicho concepto en un sentido político-constitucional («inherente a sus estructuras constitucionales políticas fundamentales»).

Si bien es cierto que el art. 4.2 TUE no ofrece una definición, per se, sí nos proporciona unos criterios relevantes para decodificar esta noción ambigua. El precepto reconduce el significado de la identidad nacional de los Estados miembros solo a aquellos elementos esenciales básicos inherentes en las estructuras políticas y constitucionales fundamentales, y por lo tanto, no incluye todas las peculiaridades constitucionales como parte de la identidad nacional de un Estado miembro. Según la perspectiva de la UE, sólo aquellas estructuras político-constitucionales que se consideren básicas y fundamentales (la esencia misma de ese orden constitucional) se tendrán en cuenta a la hora de determinar las identidades nacionales. De hecho, la identidad nacional (que ya hemos decidido que es constitucional) no necesariamente tiene que contener sólo aquellos elementos que distingan una constitución

65 Véase, por ejemplo, el sexto considerando del preámbulo de TEU ( Deseando acrecentar la solidaridad entre sus pueblos, dentro del respeto de su historia, de su cultura y de sus tradiciones») y el artículo 3 del TUE ( «La Unión respetará la riqueza de su diversidad cultural y lingüística y velará por la conservación y el desarrollo del patrimonio cultural europeo»). 
de otra ${ }^{66}$. Puede haber ciertos elementos o estructuras político-constitucionales que representen, como dirían los franceses, l'essentiel de un estado constitucional concreto, pero que a la vez sean comunes a más de un estado (la forma de monarquía parlamentaria del Reino de España o de Inglaterra es un ejemplo de esto). No obstante ello, sí que habrá casos en los que la identidad constitucional se dotará de elementos político-constitucionales fundamentales básicos únicos para un Estado miembro: la tradicional protección constitucional del nasciturus en Irlanda ${ }^{67}$ o el supracitado valor constitucional sagrado de la dignidad humana en Alemania, servirían de ejemplos.

En lo que a la identidad constitucional de los Estados miembros se refiere, estamos ante un concepto cuya base jurídica radica en el Derecho de la UE, pero cuyo contenido está íntimamente ligado a principios, valores y estructuras fundamentales e inherentes a un ordenamiento constitucional concreto. Por lo tanto, nos encontramos ante la paradoja de la identidad constitucional: es un concepto europeo (autónomo e independiente de los nacionales como muchos otros conceptos que emanan del Derecho de la $\mathrm{UE}^{68}$ ), incluso hay autores que lo han clasificado como un «principio fundacional» ${ }^{69}$ del mismo, pero también tiene contenido constitucional (aspectos fundamentales o particulares de una constitución nacional específica), contando con dos intérpretes judiciales bien distintos (TJUE y los tribunales supremos y constitucionales, respectivamente). Así, y aunque se volverá sobre ello más adelante, el carácter supranacional de la UE y su pluralismo constitucional, hace necesaria una interacción judicial constante (comúnmente conocida como «diálogo judicial» entre los tribunales nacionales —incluidos los tribunales constitucionales- y el TJUE). Besselink, aunque desde una perspectiva supranacional o europeísta, sugiere que el poder final se debería dejar al TJUE como el intérprete supremo de la legislación y conceptos del Derecho de la UE, en el que se debe incluir indudablemente el art. 4.2

${ }^{66}$ Lo que Cruz Villalón ha acuñado como «singularidad constitucional» en CRUZ VILLALÓN, P.: «La identidad constitucional de los Estados...op. cit. p. 506.

${ }^{67}$ Sin embargo, en fechas recientes (25 de mayo de 2018), el referéndum convocado en Irlanda se saldó con un $66.4 \%$ de apoyo a la reforma de la Constitución para legalizar el aborto.

68 Recordemos que, por ejemplo, el concepto de «tribunal», en lo que se refiere al órgano jurisdiccional competente para emitir una cuestión prejudicial al TJUE, es un concepto europeo que exige una serie de requisitos que no necesariamente tiene que coincidir con la definición de un estado u ordenamiento jurídico concreto de lo que es un «tribunal». El TJUE ha considerado, a través de su doctrina jurisprudencial, que los criterios que se utilizan para determinar qué denominados «tribunales» (de carácter jurisdiccional o no jurisdiccional) pueden plantear cuestiones prejudiciales, se debe tener en cuenta la función y la naturaleza jurídica de dicho tribunal dentro del sistema jurisdiccional del ordenamiento jurídico nacional, y no el nombre que se le haya dado al mismo. Esto se debe, precisamente, a que el TJUE ha establecido que el concepto de «órgano jurisdiccional» ha de entenderse como un concepto europeo, y no uno nacional, requiriendo, según su definición europea, tener un origen legal, ser permanente, poseer su jurisdicción un carácter obligatorio, tener carácter contradictorio sus procedimientos, aplicar las normas jurídicas, y ser independiente (doctrina Vaassen Gobbels, Politi, Cilfit)

${ }^{69}$ MENÉNDEZ-MENÉNDEZ, A.J.: «Una concepción alternativa...op. cit., p. 571. 
$\mathrm{TEU}^{70}$, sin embargo, también es cierto que sería inconcebible, y en mi opinión, inaceptable, si el TJUE lo hiciera de manera exclusiva, sin considerar cuidadosamente los argumentos y perspectivas de los tribunales constitucionales nacionales ${ }^{71}$ en una cuestión tan sensible y fundamental; tema sobre el cual volveremos en las conclusiones.

\subsection{La evolución de la identidad constitucional como contralímite a la primacía del Derecho de la UE}

La identidad constitucional, en el contexto de la $\mathrm{UE}^{72}$, podríamos decir que protege las características esenciales (a veces peculiares) del ordenamiento constitucional de cada Estado miembro, destacadas en sus constituciones (fácilmente identificables a través de uno de los métodos propuestos) y desarrolladas conjuntamente por sus tribunales constitucionales y por el Tribunal de Justicia de la Unión Europea al resolver conflictos entre el derecho de la UE y el derecho constitucional nacional de un Estado miembro. No obstante, también se ha convertido, como ha apuntado la doctrina, un contrapeso ${ }^{73}$ o contralímite a la aplicación categórica de la primacía del Derecho de la UE, y por tanto, se articula como una excepción a favor de los estándares constitucionales nacionales o a favor de proteger la soberanía constitucional no atribuida a la Unión. Si bien los tribunales nacionales, como jueces comunitarios ${ }^{74}$ han participado en un diálogo judicial a escala europea para resolver conflictos entre la aplicación del ordenamiento jurídico europeo frente al suyo propio, en ocasiones, han aportado argumentos relativos a sus irreconciliables valores constitucionales esencia-

${ }^{70} \mathrm{Y}$ por lo tanto, en última instancia, el TJUE, en procedimientos por infracción o procedimientos prejudiciales de interpretación o validez del Derecho de la UE, deberá determinar si ciertas normas de la UE chocan con la identidad constitucional de un Estado miembro y cuál deberá ser el equilibrio de estos dos intereses legales en conflicto.

71 BESSELINK, L. F.M.: «National and constitutional identity before and after Lisbon», Utrecht Law Review, Vol. 6, n. 3 (noviembre), 2010, p. 44.

72 Un trabajo reciente que se centra en esta cuestión lo encontramos en DI FEDERICO, G.: $L^{\prime} i$ dentità nazionale degli stati membri nel diritto dell'Unione europea, Editoriale Scientifica- CIRDE, Napoli, 2017.

73 GAMBINO, S.: «Identidad constitucional nacional, derechos fundamentales e integración europea», REDCE , n. ${ }^{\circ} 18,2012$, p. 65; FARAGUNA, P.: «Constitutional Identity in the EU -A Shield or a Sword?», German Law Journal, Vol. 18, n. ${ }^{\circ} 7,2017$, p. 1620

${ }^{74}$ Véase, por ejemplo, FERNÁNDEZ SEGADO, F.: «El juez nacional como juez comunitario europeo de derecho común. Las transformaciones constitucionales dimanantes de ello», Revista Mejicana de Derecho Constitucional, n. ${ }^{\circ} 13$ (julio-diciembre), 2005, pp. 1-26; MAYORAL DÍAZ-ASENSIO, J.A., BERBEROFF AYUDA, D., y ORDÓÑEZ SOLÍS, D.: «El juez español como juez de la Unión Europea, Revista española de derecho europeo», n. ${ }^{\circ}$ 48, 2013, pp. 127-152; Alonso García, R.: El juez nacional en la encrucijada europea de los Derechos Fundamentales, Civitas, Madrid, 2014; MARTÍN REBOLLO, L.: «Sobre el papel del juez nacional en la aplicación del Derecho europeo y su control», Revista de Administración Pública, n. 2000 (mayo-agosto), 2016, pp. 173-192; y NIEVA FENOLL, J.: «La actuación de oficio del juez nacional europeo Justicia», Revista de derecho procesal, n. ${ }^{\circ} 1,2017$, pp. 181-210. 
les (a través de la cláusula de identidad nacional), para minorar el efecto del principio de primacía.

En efecto, diversos tribunales constitucionales y supremos de los Estados miembros han cuestionado la prevalencia del Derecho de la UE sobre sus propias constituciones nacionales, clasificando, como se ha apuntado antes, a la UE como una organización internacional ordinaria y a los Estados miembros como dueños Tratados. En consecuencia, sostienen que el Derecho de la UE no tiene primacía absoluta sobre las constituciones nacionales y que ellos, los tribunales constitucionales nacionales, como garantes supremos y guardianes de sus constituciones, tienen la última palabra, especialmente cuando están en juego valores constitucionales y estándares de protección de ciertos derechos fundamentales (bastaría con citar asuntos históricos como los Solange y Maastricht-Urteil ${ }^{75}$ ).

Tal y como clasifica Groppi, en un análisis comparado de la posición de los tribunales constitucionales y supremos de la UE sobre la primacía del Derecho de la UE, existen diferentes niveles de aceptación o rechazo a la primacía del Derecho de la $\mathrm{UE}^{76}$. En otras palabras, los tribunales constitucionales nacionales entienden y usan la identidad constitucional como el último reservorio legítimo de su poder originario no conferido a la UE, y más específicamente, como base para reclamar la inaplicación del Derecho de la UE a favor de elementos esenciales y fundamentales propios de su orden constitucional. El respeto por las identidades nacionales (como ya se ha argumentado «constitucionales») de los Estados miembros se ha convertido en un contraargumento válido contra el funcionamiento o la aplicación efectiva del Derecho de la UE. En tal sentido, se ha afirmado que su función principal es negativa: sirve como un contralímite a la aplicación incondicional de la legislación de la UE.

$\mathrm{Y}$, sin embargo, esta afirmación, cuya base jurídica se fundamenta precisamente en el propio Derecho de la UE, parece contradecir otros aspectos clave de la misma, que incluso podrían considerarse una de las principales y distintivas características que hacen a la UE identificable y única: la UE forma un orden jurídico propio e independiente al de su Estados miembros (principio de autonomía) y, en caso de contradicción, el Derecho de la UE prevalece sobre el derecho de sus Estados miembros, incluidas sus constituciones (principio de primacía), todo ello de conformidad con la jurisprudencia asentada del TJUE que inauguraron asuntos tales como Van Gend En Loos, Costa ENEL y Simmenthal.

75 Véase los asuntos Solange I, 37 BverfGE 271 (1974), Solange II, 73 BverfGE 378 (1986) y Maastricht 15 BVerfGE 89 (1993).

${ }^{76}$ GROPPI, T.: «La «primauté» del Derecho europeo sobre el Derecho constitucional nacional: un punto de vista comparado», REDCE, n. ${ }^{\circ} 5$ (enero-junio), 2006, pp. 225-243. Según ella, están aquellos que no aceptan la primacía de la legislación de la UE (Dinamarca, Estonia, Letonia y Lituania), aquellos que, en principio, no aceptan, pero dejan abierta la posibilidad (Polonia, Francia, Eslovenia, Hungría, España y Holanda), aquellos que aceptan la primacía pero tienen límites materiales (Suecia, Finlandia, Grecia, Portugal, Italia, Alemania, Reino Unido) y aquellos que aceptan abierta y completamente la primacía de la ley de la UE (Austria, Holanda, Rumania, Malta, Croacia, Chipre e Irlanda). 
Es indudable la contribución del TJUE al proyecto de construcción europeo, y concretamente, a la constitucionalización de la UE, ha reflejado su posición como actor clave en la interpretación del Derecho primario de la UE, entre el que se debe incluir el art. 4.2 TEU; pues a fin de cuentas, como se ha señalado anteriormente, se trata de un concepto llamado a ser desarrollado por los tribunales. Si analizamos la jurisprudencia del TJUE previa a la reforma del Tratado de Lisboa, si bien la noción de identidad constitucional (o, en aras a ser fiel al texto origen, «nacional») apenas se usó en su fundamentación jurídica, sí que tuvo en cuenta y aceptó, en varias ocasiones, principios del derecho constitucional nacional como argumento legítimo para asumir ciertas restricciones a las libertades fundamentales de la UE. De hecho, en muchos casos el TJUE ha reconocido un cierto «margen de apreciación» o «margen de discrecionalidad», y ha tenido que ir transformando su doctrina sobre la aplicación incondicionada del Derecho de la UE a favor de ciertos intereses constitucionales nacionales, lo que se revela más claramente con el uso de la excepción del orden público.

La transformación del intérprete supremo europeo es clara si consideramos la doctrina originaria del TJUE y su evolución de una primacía absoluta e incondicionada (Asunto InternationaleHandelsgesellschaft) ${ }^{77}$ hacia la admisión de excepciones cuando la relevancia de una norma constitucional particular justificara una necesaria y relativa aplicación ${ }^{78}$ del Derecho de la UE (Asunto Omega ${ }^{79}$. Sin embargo, después de la constitucionalización de la cláusula de identidad tras la reforma del Tratado de Lisboa, se han presentado numerosos argumentos de identidad constitucional ante el TJUE por parte

77 Véase apartado 3 del Asunto C-11/70, STJUE de 17 de diciembre de 1970: "que, en efecto, al Derecho nacido del Tratado, surgido de una fuente autónoma, por su propia naturaleza no se le puede oponer ninguna norma del Derecho nacional, sin perder su carácter comunitario y sin que se cuestione el fundamento jurídico de la Comunidad misma; que la alegación de violaciones de los derechos fundamentales, tal como están formulados por la Constitución de un Estado miembro, o de los principios de una estructura constitucional nacional no puede afectar a la validez de un acto de la Comunidad o a su efecto en el territorio de dicho Estado».

78 VON BOGDANDY, A., y SCHILL, S.: «Overcoming Absolute Primacy: Respect for National Identity Under the Lisbon Treaty», Common Market Law Review, n. ${ }^{48,}$ 2011, pp.1418-1420.

79 Véase apartados 30 y 41 del Asunto C-36/02, STJUE de 14 de octubre de 2004: "the concept of "public policy" in the Community context, particularly as justification for a derogation from the fundamental principle of the freedom to provide services, must be interpreted strictly, so that its scope cannot be determined unilaterally by each Member State without any control by the Community institutions (...)Thus, public policy may be relied on only if there is a genuine and sufficiently serious threat to a fundamental interest of society (...). In the light of the above considerations, the answer to the question must be that Community law does not preclude an economic activity consisting of the commercial exploitation of games simulating acts of homicide from being made subject to a national probibition measure adopted on grounds of protecting public policy by reason of the fact that that activity is an affront to human dignity». Este asunto es de especial relevancia pues la prohibición de juegos de pistola láser que implicasen la simulación de actos de violencia y la representación de homicidio en Alemania por considerarse contrario a la Constitución alemana (y concretamente a su cláusula única anteriormente mencionada sobre el respeto de la dignidad humana) pero, a la vez, dicha prohibición vulneraba la libre circulación de servicios para proveedores de este tipo de juego recreativo (algo prohibido en la UE). Sin embargo, el TJUE permitió esta restricción a la libre circulación de bienes y servicios después de llevar a cabo un test proporcionalidad de las medidas adoptadas, concluyendo que la medida no fue más allá de lo necesario para alcanzar el objetivo de interés público perseguido. 
de los tribunales supremos y constitucionales de los Estados miembros; en ocasiones argumentos constructivos y legítimos, y en otras, doblegando la finalidad original de dicha cláusula. De hecho, en el asunto Michaniki io, el Abogado General Maduro ya introdujo una reflexión muy interesante sobre las diferentes funciones que una remisión a la «identidad nacional» (constitucional) podría cumplir: (a) reivindicar la preservación de la identidad nacional, como motivo legítimo de excepción, para justificar una excepción a la aplicación de las libertades fundamentales de circulación; (b) permitir el desarrollo jurídico-constitucional de cada Estado sobre su propia acepción de lo que constituye su identidad constitucional, y, a su vez, habida cuenta de estas particularidades nacionales y estándares desarrollados, presentarlas como interés legítimo para justificar un obstáculo a una libertad fundamental de circulación; (c) justificar un argumento basado en medidas constitucionales que completan la normativa europea para garantizar el respeto, en su territorio, de principios, valores, normas y derechos que se reconocen o subyacen en dicha legislación ${ }^{81}$. Todo lo cual no significa, lógicamente, que la obligación de respetar las identidades constitucionales de los Estados miembros deba de entenderse como absoluta, consintiendo que los Estados miembros se escuden en sus particularidades constitucionales para eludir el Derecho de la UE, pudiendo sólo ser tenidas en cuenta y aceptadas, en la medida en que estén comprendidas dentro de ese margen de apreciación, ahora optimizado, y sean proporcionales.

Aquí cabe traer a colación, y de manera muy resumida, una serie de hitos jurisprudenciales y casos ilustrativos en los que se ve claramente la remisión a una identidad nacional (entendida, nuevamente, como constitucional) por parte de los intérpretes supremos nacionales al intérprete supremo europeo. El Asunto Sayn-Wittgenstein relativo a la igualdad formal y la prohibición de títulos de nobleza dio pie a considerar y aceptar la forma republicana de gobierno como parte de la identidad constitucional de Austria ${ }^{82}$. En el Asunto Runevic relativo al principio de no discriminación por razón de nacionalidad y la obligación de una normativa nacional de transcribir los nombres y apellidos de las personas físicas en los documentos acreditativos del estado civil con arreglo a las normas de grafía de la lengua oficial nacional, encontramos una aceptación del idioma nacional (en este caso lituano) como seña de su identidad constitucional, aunque finalmente, la medidas nacionales para promoverlo y protegerlo no superaran el examen de proporcionalidad ${ }^{83}$. Y, en similar sentido, me limito a hacer mera referencia a otros dos asuntos que han reflejado pro-

80 Véase Asunto C-213/07, STJUE de 16 de diciembre de 2008.

81 Véase Conclusiones del Abogado General de 8 de octubre de 2008, apartados 31-33.

82 Asunto C-208/09, STJUE de 22 de diciembre de 2010.

83 Asunto C-391/09, STJUE de 12 de mayo de 2011, apartados 84-88. Para un análisis más detallado sobre la jurisprudencia sobre diversidad lingüística y la lengua como parte de la identidad nacional, véase CORRIAS, L.: «National Identity and European Integration: the Unbearable Lightness of Legal Tradition», European Papers, Vol. 1, n. ${ }^{\circ}$ 2, 2016, pp. 388-389 y GUASTAFERRO, B.: « Beyond the Exceptionalism of Constitutional Conflicts : The Ordinary Functions of the Identity Clause», Jean Monnet Working Paper Series n. ${ }^{\circ} 1,2012$, pp. 47-48. 
blemáticas análogas, a saber, $O » B r i e n^{84}$ y $\operatorname{Las}^{85}$. Adicionalmente, el Asunto Dansk Industri/Ajos, relativo a la anulación de disposiciones nacionales contrarias al principio general de no discriminación por motivos de edad en el ámbito del empleo, dio lugar a que, a pesar de las consideraciones del TJUE en su sentencia prejudicial, el Tribunal Supremo danés no las llegara a aceptar por motivos de su identidad o mandato constitucional $^{86}$. Y, por último, la saga Taricco es de especial relevancia, pues versaba sobre una posible vulneración del principio de legalidad penal, como principio fundamental de la identidad constitucional italiana, y por el que el propio Tribunal Constitucional italiano remitió al TJUE una cuestión prejudicial, sobre un tema presuntamente aclarado en una instancia inferior, para que reconsiderara su interpretación anterior en vista de las cuestiones fundamentales en juego ${ }^{87}$.

En particular, en este último asunto, se discutía la contradicción entre los límites máximos del plazo de prescripción italianos a ciertos procedimientos penales relativos al fraude fiscal relacionado con el IVA en Italia y la protección efectiva de los intereses financieros de la UE (según el art. 325 TFUE). Ello se debía a que los plazos de prescripción resultaban ser demasiado cortos para el colapsado sistema de justicia italiano, lo cual tenía como resultado que un número significativo de personas presuntamente culpables de fraude grave al IVA quedaban impunes. Ante este conflicto, el tribunal italiano presentó una cuestión prejudicial para aclarar la interpretación del Derecho de la UE y la conciliación de estos dos intereses encontrados. El TJUE, en este sentido, en su primera sentencia Taricco (2015) obligó a los tribunales penales italianos a no aplicar los plazos nacionales de prescripción de delitos en los casos de fraude al IVA, a fin de dar pleno efecto al artículo 325 TFUE $^{88}$. Sin embargo, tras el

84 Asunto C-393/10, STJUE de 1 de marzo de 2012.

85 Asunto C-202/11, STJUE de 16 de abril de 2013.

86 Asunto C-441/14, STJUE de 19 de abril de 2016 y Asunto n. ${ }^{\circ}$ 15/2014 y sentencia de 6 de diciembre de 2016 del Tribunal Supremo danés. Para un análisis más detallado sobre este caso particular, véase ŠADL, U., y MAIR, S.: «Mutual Disempowerment: Case C-441/14 Dansk Industri, acting on behalf of Ajos A/S v Estate of Karsten Eigil Rasmussen and Case no. 15/2014 Dansk Industri (DI) acting for Ajos A/S v The estate left by A», European Constitutional Law Review, n. ${ }^{\circ}$ 13, 2017, pp. 347368 y RASK MADSEN, M., PALMER OLSEN, H., y SADL, U.: «Competing Supremacies and Clashing Institutional Rationalities: The Danish Supreme Court's Decision in the Ajos Case and the National Limits of Judicial Cooperation», University of Copenhagen Faculty of Law Legal Studies Research Paper Series n. 32,2017 , pp. 1-17.

87 Asunto C-105/14, STJUE de 8 de septiembre de 2015 y Asunto C-42/17, STJUE de 5 de diciembre de 2017.

${ }^{88}$ Véase apartado 58 de la STJUE de 8 de septiembre de 2015: «Habida cuenta de las anteriores consideracionest....) una normativa nacional sobre la prescripción de las infracciones penales como la establecida por las disposiciones nacionales controvertidas, que disponia, en el momento en que se produjeron los hechos del litigio principal, que la interrupción de la prescripción en el marco de un procedimiento penal relativo a fraudes graves en materia de IVA tenía como consecuencia ampliar el plazo de prescripción en tan solo una cuarta parte de su duración inicial, puede ser contraria a las obligaciones que el artículo 325 TFUE, apartados 1 y 2, impone a los Estados miembros, siempre que dicha normativa nacional impida imponer sanciones efectivas y disuasorias en un número considerable de casos de fraude grave que afecten a los intereses financieros de la Unión, o establezca en el caso de fraudes que afecten a los intereses financieros del Estado miembro de que se trate plazos de 
firme desacuerdo de la instancia superior italiana, su Tribunal Constitucional, y su análisis jurídico sobre la identidad constitucional italiana, a la luz de este uso legítimo y justificado del principio de legalidad, como parte inherente de la identidad nacional (entendida, recordemos una vez más, como constitucional), el TJUE revocó dicha obligación incondicional en Taricco II (2017), pero, por supuesto, también sobre la base de su propia interpretación del principio de legalidad (como denominador común de las tradiciones constitucionales y de la jurisprudencia del Tribunal Europeo de Derecho Humanos que han nutrido el Derecho de la UE) ${ }^{89}$, concluyendo que la aplicación y la primacía del Derecho de la UE prevalecería, inaplicando la norma nacional en conflicto «a menos que la mencionada inaplicación implique una violación del principio de legalidad de los delitos y las penas, debido a la falta de precisión de la ley aplicable o debido a la aplicación retroactiva de una legislación que impone condiciones de exigencia de responsabilidad penal más severas que las vigentes en el momento de la comisión de la infracción» ${ }^{90}$. Un análisis interesante de las consecuencias jurídico-constitucionales de este caso se ha llevado a cabo por Romboli y su proposición de una aplicación más «dúctil» $\mathrm{y}$ «mesurada» de lo que califica como «principio de los contra-límites» ${ }^{91}$. No obstante, cabe recordar que Taricco guarda una gran similitud con el asunto Melloni

prescripción más largos que en el caso de fraudes que afecten a los intereses financieros de la Unión, extremo que corresponde verificar al órgano jurisdiccional nacional. Incumbe a éste garantizar la plena eficacia del artículo 325 TFUE, apartados 1 y 2, dejando si es preciso sin aplicación las disposiciones del Derecho nacional que impidan al Estado miembro de que se trata dar cumplimiento a las obligaciones que le impone dicho artículo» [énfasis nuestro].

89 Véase apartados 51 y 53-58 de la sentencia de 5 de diciembre de 2017: «A este respecto, procede recordar la importancia que reviste, tanto en el ordenamiento jurídico de la Unión como en los ordenamientos jurídicos nacionales, el principio de legalidad de los delitos y las penas, en sus exigencias relativas a la previsibilidad, la precisión y la irretroactividad de la Ley penal aplicable (...) Además, el principio de legalidad de los delitos y las penas forma parte de las tradiciones constitucionales de los Estados miembros (...) el requisito de la precisión de la ley aplicable, que es inherente a este principio, implica que la ley defina de manera clara las infracciones y las penas con las que se castigan. Este requisito se cumple cuando el justiciable puede saber, a partir del texto de la disposición pertinente y, si fuera necesario, con ayuda de la interpretación que de ella hacen los tribunales, qué actos y omisiones desencadenan su responsabilidad penal (...) el principio de irretroactividad de la ley penal se opone, concretamente, a que un juez pueda, durante un procedimiento penal, bien sancionar penalmente un comportamiento que no está probibido por una norma nacional adoptada antes de la comisión de la infracción imputada, bien agravar el régimen de responsabilidad penal de aquellos que sean objeto del mencionado procedimiento (...) Por otra parte, los requisitos mencionados en el apartado 58 de la presente sentencia suponen un obstáculo a que, en los procedimientos que afectan a personas acusadas de haber cometido infracciones en materia del IVA antes de que se pronunciase la sentencia Taricco, el juez nacional no aplique las disposiciones del Código Penal controvertidas. En efecto, el Tribunal de Justicia ya ha destacado, en el apartado 53 de la mencionada sentencia, que, debido a la inaplicación de esas disposiciones, podrían imponerse a esas personas sanciones que, con toda probabilidad, habrían evitado si se bubieran aplicado las mencionadas disposiciones. Así, esas personas podrían quedar sujetas retroactivamente a condiciones de exigencia de responsabilidad penal más severas que las vigentes en el momento de la comisión de la infracción».

90 Véase el apartado 62 y el fallo de la sentencia de 5 de diciembre de 2017.

91 ROMBOLI, S.: «"Los contra-límites en serio" y el caso Taricco: el largo recorrido de la teoría hasta la respuesta contundente pero abierta al diálogo de la Corte Constitucional italiana», REDCE, n. ${ }^{\circ} 28$, p. 16 de la versión disponible en: http://www.ugr.es/ redce/REDCE28/articulos/06_S_ROMBOLI.htm 
en tanto en cuanto no se trataba de desafiar la primacía del Derecho de la UE, sino de subrayar que un mandato constitucional esencial a su ordenamiento resultaba ser un obstáculo para la plena aplicación del mismo, dado la diferente interpretación de un principio fundamental (de un derecho fundamental en Melloni), ofreciendo un mayor grado de protección y otorgando un trato más favorable al individuo ${ }^{92}$.

El TJUE le ha atribuido peso jurídico a determinados aspectos constitucionales invocados como parte de su análisis de conciliación jurídica, intentando respetar aquellos elementos y estructuras inherentes a la identidad constitucional del estado miembro en cuestión ${ }^{93}$. Si bien los tribunales nacionales normalmente desempeñan su función de juez de Derecho de la UE y de «agentes de la integración» ${ }^{94}$, los intérpretes supremos de cada ordenamiento constitucional tienen encomendado un mandato constitucional especial ${ }^{95}$ de proteger la integridad de su orden constitucional, lo que en la práctica de la pluralidad constitucional y gobernanza multinivel ${ }^{96}$, evidentemente, supone cierta resistencia a una primacía absoluta del Derecho de la UE.

Empero, resulta oportuno concluir que, en primer lugar, ciertos tribunales constitucionales y supremos han sido más cautos con su auctoritas constitutionalis, mientras que otros en cambio, han pasado de utilizar «escudos blandos» a unos bien «duros»,

92 De gran interés resulta en tal sentido la confrontación de jurisprudencias del propio TJUE efectuada por UGARTEMENDIA ECEIZABARRENA, J.I.: «La saga Taricco. Las últimas instantáneas jurisdiccionales sobre la pugna acerca de los derechos fundamentales en la Unión Europea», Revista General de Derecho Constitucional, n. ${ }^{\circ} 27,2018$, p. 25: cabe concluir que si se asume que la no inaplicación judicial de las normas penales italianas relativas a la prescripción penal (por respetar el estándar italiano del principio de legalidad penal) entra dentro del margen de actuación estatal («situación Akerberg»), y no contraviene el Derecho de la Unión, nada habrá cambiado en realidad respecto a la mencionada jurisprudencia Akerberg/Melloni. Pero si se considera que el respeto del principio de legalidad penal entendido según el estándar nacional se salva a costa de excepcionar la inaplicación judicial de las normas penales sobre la prescripción penal (excepción al cumplimiento de una obligación europea), entonces hay que colegir que nos encontramos en un supuesto que excede o supera la «situación Akerberg», pues se estaría contraviniendo el principio de primacía (la inaplicación de la actuación nacional contraria al Derecho de la Unión es la manifestación o efecto principal del principio de primacía). Se estaría haciendo ceder al Derecho de la Unión (primacía) ante el respeto del estándar nacional de los Derechos Fundamentales. Nos encontraríamos, en consecuencia, ante un visible retraimiento de la jurisprudencia del TJUE en relación al juego del principio de primacía respecto al Derecho estatal de los Derechos Fundamentales».

93 Aunque esto, a su vez, ha propiciado una divergencia de las disposiciones integradoras clásicas del Derecho de la UE según apunta BURGORGUE-LARSEN, L.: «A Huron at the Kirchberg Plateau or a few naive thoughts on constitutional identity in the case-law of the Judge of the European Union», en SAIZ ARNAIZ, A., y ALCOBERRO ILIVINA, C. (eds) National Constitutional Identity and European Integration, Intersentia-Law and Cosmopolitan Values, Cambridge, Vol. 4, 2013, pp. 275-304.

94 POPELIER, P.: «Europe Clauses» and Constitutional Strategies in the Face of Multi-Level Governance...op. cit., p. 313.

95 CLAES, M.: The National Courts' Mandate in the European Constitution, Hart Publishing, Oxford, 2006.

96 Interesante resulta los apuntes de Mayer, sobre esta cuestión en MAYER, F.C.: «Multilevel Constitutional Jurisdiction», EN VON BOGDANDY, A., y BAST, J. (Eds.), Principles of European Constitutional Law, Hart Publishing, Oxford, 2. ${ }^{\text {e ed., }} 2009$. 
y en algunas ocasiones, con actitud desafiante ${ }^{97}$, han utilizado la cláusula de identidad como verdaderas «espadas» ${ }^{98}$ contra el principio de primacía, rebelándose contra la efectiva aplicación del Derecho de la UE. Los contralímites, en forma de identidad nacional, consagrados en el Derecho de la UE, han dejado de ser «declarados pero no practicados ${ }^{99}$ como evidenciaba en su día la sentencia alemana Lisboa ${ }^{100}$ y ello ha creado un verdadero duelo de «titanes» ${ }^{101}$ jurisdiccionales, en el que los órganos jurisdiccionales nacionales supremos se han visto legitimados para limitar la primacía del Derecho de la UE con el fin de evitar la invasión total del ordenamiento supranacional al nacional, la pérdida completa de soberanía estatal, o por lo que han apostado algunos autores, como alternativa a un principio constitucional de soberanía ${ }^{102}$. En segundo lugar, cabe afirmar que todo lo anterior indica, igualmente, cuando menos, la «apertura» del TJUE hacia la posibilidad, aunque todavía excepcional y limitadamente justificada, de que los ordenamientos jurídicos nacionales inapliquen el Derecho de la UE en aras a preservar y proteger el núcleo duro, inviolable si se prefiere, de sus ordenamientos constitucionales: la llamada identidad constitucional.

\section{ARRIESGADO ACERCAMIENTO ALTERNATIVO A LA IDENTIDAD CONSTITUCIONAL EUROPEA: MÁS ALLÁ DE LAS «TRADICIONES CONSTITUCIONALES COMUNES»}

Del mismo modo que se ha procedido a puntualizar la identidad constitucional de un estado a través de los métodos de identificación expuestos, que analizan aspectos concretos de su ordenamiento constitucional (tanto dentro como fuera de su texto constitucional), y en aras a contribuir a la mejora de la disciplina constitucional

$97 \mathrm{O}$, como algunos autores han llamado, un «auténtico desafío al acervo comunitario», véase, en este sentido, GAMBINO, S.: «Identidad constitucional nacional, derechos fundamentales e integración europea», REDCE, n. ${ }^{\circ} 18,2012$, p. 57.

98 FARAGUNA, P.: «Constitutional Identity in the EU -A Shield or a Sword...op. cit. pp. 16291631 y KONSTADINIDES, T.: «Constitutional Identity as a Shield and as a Sword: The European Legal Order within the Framework of National Constitutional Settlement», Cambridge Yearbook of European Legal Studies, Vol. 13, 2011, pp. 195-218.

99 GAMBINO, S.: «Identidad constitucional nacional...op. cit, p. 70.

100 Asunto Lissabon-Urteil, Sentencia del Tribunal Constitucional Federal Alemán de 30 de junio de 2009. Disponible en inglés en: http://www.bundesverfassungsgericht.de/entscheidungen/ es20090630_2bve000208en.html y MAYER, F.: «Rashomon in Karlsruhe: A reflection on democracy and identity in the European Union», International Journal of Constitutional Law, Vol. 9, n. ${ }^{\circ}$ 3-4, 2011, pp. 757-785; CASTILLO DE LA TORRE, F.: «La sentencia del Tribunal Constitucional Federal alemán de 30.06.2009, relativa a la aprobación del Tratado de Lisboa - análisis y comentarios», Revista de Derecho Comunitario Europeo, n. 34 (septiembre/diciembre), 2009, pp. 969-1010.

101 GUALCO, E.: «"Clash of Titans” 2.0. From Conflicting EU General Principles to Conflicting Jurisdictional Authorities: The Court of Justice and the Danish Supreme Court in the Dansk Industri Case», European Papers European Forum, Insight del 26 del marzo de 2017, pp. 1-7.

102 BELOV, M.: «The Functions of Constitutional Identity...op. cit., p. 89 
en lo que atañe a la integración europea, procederemos a postular una posible, aunque indudablemente incompleta, definición de lo que constituye la identidad constitucional de la Unión Europea.

En primer lugar, si examinamos el preámbulo de la Constitución de la Unión Europea desde el Tratado de Lisboa (es decir, los preámbulos del TUE, del TFUE y la CDFUE), adelantando, por supuesto, que, como se ha apuntado anteriormente, desde el fallido Tratado Constitucional Europeo, no existe de iure una Constitución Europea, pero sí que de facto podemos atribuirle una al ordenamiento europeo; lo que ha acuñado Bar Cendón, como la «Constitución europea material» ${ }^{103}$ y lo han denominado otros como «sustancia constitucional» ${ }^{104}$.

Así, si examinamos los preámbulos de estos tres documentos jurídicamente vinculantes y directamente aplicables, en los que se plasma una historia, como cualquier otra, constitucional, encontramos una serie de términos, conceptos, valores y principios recurrentes y significativos que podrían adecuadamente indicar la identidad constitucional de la UE. De esta forma, resulta pertinente subrayar que términos como «paz», «seguridad», «valores comunes», «tradiciones», «democracia», «estado de Derecho», «dignidad humana», y «derechos», entre otras, son los elementos más repetidos en estos tres textos. Efectivamente, la UE y los Estados miembros que la componen comparten una historia común: una devastadora guerra mundial que no debía repetirse y un objetivo primordial de mantener la paz en el continente (y en este sentido sigue siendo el mayor éxito de construcción jurídica pacífica del mundo). No obstante, la diferenciación, diversidad y pluralismo en el continente ha sido también patente en el proceso de construcción europeo: «en un continente que ha experimentado de todo, del nacionalismo más oclusivo y el colonialismo más agresivo al internacionalismo más abierto y cooperativo entre los pueblos, de la tolerancia a la intolerancia, de la concepción individualista y liberal de la vida social a la totalitaria y orgánica, del dogma cristiano a la libertad de conciencia, de la libertad de la ciencia y la técnica a su subordinación a verdades metafísicas, de la connivencia entre política y religión en el gobierno de los pueblos a la laicidad

103 Véase, por todos, BAR CENDÓN, A.: «La Constitución de la Unión Europea: contexto, reforma y virtualidad», op. cit. De modo similar, también véase LÓPEZ CASTILLO, A.: «La Unión Europea «en constitución» y la Constitución estatal en (espera de) reformas. A propósito de la DTC 1/2004, de 13 de diciembre» en LÓPEZ CASTILLO, A., SAIZ ARNAIZ, A., y FERRERES COMELLA, V. (dirs) Constitución Española y Constitución Europea, Centro de Estudios Políticos y Constitucionales, Madrid, 2005, pp. 13-76; ALDECOA LUZARRAGA, F. Y GUINEA LLORENTE, M.: «El rescate sustancial de la Constitución Europea a través del Tratado de Lisboa: la salida del laberinto», Real Instituto Elcano-Working Paper n. ${ }^{\circ}$ 9, 2008; PEREIRA DA SILVA, V.: «Una reflexión desde Granada sobre la constitución europea», Revista de derecho constitucional europeo, ${ }^{\circ} 22$ (La dimensión de la Administración Pública en el contexto de la globalización (III), 2014, pp. 285-296.

104 JIMENA QUESADA. L., y TAJADURA TEJADA, J.: «La prehistoria y la historia del derecho constitucional europeo...op. cit., p. 32: «Desde esta óptica, aunque la Unión no tenga una Constitución, puesto que su existencia se fundamenta en un Tratado Internacional, el Tratado de Lisboa, es cierto que encontramos en ella en tanto que Comunidad de Derecho, una serie de elementos: declaración de derechos, división de poderes (borizontal y vertical), principio de primacía de los Tratados y del derecho europeo sobre el derecho nacional), que permiten hablar de la «sustancia constitucional» del Tratado». 
de sus relaciones, de la integración de etnias y culturas a la persecución racial, etcétera, la identidad no puede ser la suma de todo ello, pues no pueden convivir pacíficamente; más bien, ha de ser el producto de una selección: preguntarse cuál es la identidad no significa preguntarse qué somos, pero sí qué queremos ser. Nada, pues, más cultural y menos objetivo» ${ }^{105}$.

Sin entrar a valorar las vertientes de integración ni las tres archiconocidas perspectivas acerca de la concepción europea que desarrolla Rubio Llorente, cabe al menos hacer una breve referencia a la visión federalista de la UE que explica Solozábal, integradora de un demos que, a pesar de tener una base diversificada, también se fundamenta sobre sobre una aceptación común de determinados valores y principios. La clave de esa adhesión es precisamente "unos mismos referentes espirituales o ideológicos, a modo del patriotismo constitucional de Habermas» ${ }^{106}$, acercándose, a su vez, con la tesis weileriana sobre la concepción cultural para referirse al proyecto compartido del demos europeo. En esa línea, ha llamado este mínimo denominador común como la "permanente identidad constitucional europea», parte de una nación con «base espiritual indudable y proyectada hacia el futuro, en la línea de la idea de nación de Renan, y con la solidaridad que genera el tener una estructura política común» ${ }^{107}$.

En cualquier caso, en lo que a los aspectos más sustantivos se refiere, los elementos supracitados reflejan cuál es el patrimonio constitucional común europeo (lo que muchos instrumentos, incluida la CDFUE y el propio TJUE han llamado «tradiciones constitucionales comunes de los Estados miembros»). Y si bien es cierto que la mayoría de estos elementos, principios, valores y derechos son universalmente reconocidos y están igualmente recogidos en las constituciones nacionales del mundo, aún podría ser útil acercarse a una definición de lo que constituyen las características esenciales del proceso de constitucionalización europeo. De hecho, uno puede, y debe, argumentar, que la identidad constitucional nacional de los Estados miembros y la identidad constitucional europea no son excluyentes, sino todo lo contrario, pues esta se construye sobre los cimientos de aquellas.

Además, es bien conocido que el respeto a los derechos fundamentales y los valores humanistas han constituido uno de los grandes signos distintivos de identidad del proyecto de integración europea ${ }^{108}$, y, en este sentido, la UE ha sido y es una comunidad político-jurídica que muestra una identidad común europea: tal y como apunta Von Bogdandy ${ }^{109}$ por un pasado y origen común, pero sobre todo, por unos valores

105 ZAGREBELSKY, G.: «LA IDENTIDAD EUROPEA», ReDCE. Año 6, n. ${ }^{\circ} 12$ (julio-diciembre), 2009, pp. 20-21.

106 SOLOZÁBAL ECHAVARRÍA, J.J.: «Identidad Constitucional Europea», El Cronista del Estado Social y Democrático de Derecho, n. ${ }^{\circ} 76,2018$, p. 27.

107 SOLOZÁBAL ECHAVARRÍA, J.J.: "Identidad Constitucional Europea...op. cit., p. 28

108 BAR CENDÓN, A.: «La Unión Europea como unión de valores y derechos: teoría y realidad», Teoría y Realidad Constitucional, n. ${ }^{\circ} 33,2014$, p. 110.

109 VON BOGDANDY, A.: «The European constitution and European identity: Text and subtext of the Treaty establishing a Constitution for Europe», International Journal of Constitutional Law, Vol. 3 , n. $2 / 3,2005$, pp. 299-306. 
comunes y un destino común ${ }^{110}$. De manera muy similar encontramos, en el preámbulo de la CDFUE esos valores y destino comunes: «Los pueblos de Europa, al crear entre sí una unión cada vez más estrecha, han decidido compartir un porvenir pacífico basado en valores comunes. Consciente de su patrimonio espiritual y moral, la Unión está fundada sobre los valores indivisibles y universales de la dignidad bumana, la libertad, la igualdad y la solidaridad, y se basa en los principios de la democracia y el Estado de Derecho. Al instituir la ciudadanía de la Unión y crear un espacio de libertad, seguridad y justicia, sitúa a la persona en el centro de su actuación. La Unión contribuye a defender y fomentar estos valores comunes dentro del respeto de la diversidad de culturas y tradiciones de los pueblos de Europa, así como de la identidad nacional de los Estados miembros».

En segundo lugar, si observamos los criterios esenciales de adhesión de un estado europeo a la UE, encontramos que, curiosamente, el primero de los requisitos de los archiconocidos criterios de Copenhague, con un claro componente político-constitucional, es precisamente garantizar instituciones estables que garanticen la democracia, el Estado de Derecho, los derechos humanos y el respeto y la protección de las minorías. En otras palaras, para unirse a la comunidad supranacional europea encontramos que existen valores y principios específicos (también, de manera más genérica el respeto de los derechos y la dignidad humana como «núcleo material» de la UE ${ }^{111}$ ) que los Estados deben aceptar, y con los que sus ordenamientos deben bautizarse, como condiciones sine qua non para poder pertenecer a ella; condiciones que, por otra parte, resulta coinciden con los valores consagrados por el conjunto de preámbulos de la Constitución europea material. Todo lo cual ejemplifica ciertas características político-constitucionales esenciales de la UE como organización supranacional, que, aunque en origen se erigiera sobre la base de una integración económica, ya proclamaba sus objetivos y aspiraciones a favor de convertirse en una unión político-constitucional supranacional cada vez más cercana: «La Unión Europea ha sido definida como una Comunidad de Derecho en la que todos sus miembros comparten unos mismos valores. Ello implica que sólo pueden ingresar en la Unión aquellos Estados que asumen un concreto orden

110 Según, por ejemplo, el preámbulo del TUE «valores universales de los derechos inviolables e inalienables de la persona, así como la libertad, la democracia, la igualdad y el Estado de Derechot... fadhesión a los principios de libertad, democracia y respeto de los derechos humanos y de las libertades fundamentales y del Estado de Derechot...)». Véase también estos reflejados en el artículo 2 TUE: "La Unión se fundamenta en los valores de respeto de la dignidad humana, libertad, democracia, igualdad, Estado de Derecho y respeto de los derechos humanos, incluidos los derechos de las personas pertenecientes a minorías. Estos valores son comunes a los Estados miembros en una sociedad caracterizada por el pluralismo, la no discriminación, la tolerancia, la justicia, la solidaridad y la igualdad entre mujeres y hombres». Y, de modo similar, según, por ejemplo, el preámbulo del TUE: «sentar unas bases firmes para la construcción de la futura Europa (...) acrecentar la solidaridad entre sus pueblos, dentro del respeto de su bistoria, de su cultura y de sus tradiciones, (...) fortalecer el funcionamiento democrático y eficaz de las instituciones, (...) fontinuar el proceso de creación de una unión cada vez más estrecha entre los pueblos de Europa (...)salvar para avanzar en la vía de la integración europea».

111 ALCOCEBA GALLEGO. M.A.: «La integración diferenciada en el Tratado de Lisboa o la ampliación de la Europa a la carta sobre la construcción de una nueva Unión Europea», en FERNÁNDEZ LIESA, C.R., DÍAZ BARRADO, C.M., ALCOCEBA GALLEGO, M.A., y MANERO SALVADOR, A. (Coords) El tratado de Lisboa: análisis y perspectivas, 2008. 
material de valores: "respeto a la dignidad humana, libertad, democracia, igualdad, Estado de Derecho y respeto a los derechos humanos». No debe quedar ninguna duda de que si un Estado no supera el test de efectividad respecto a los principios de la democracia constitucional no puede ingresar en la Unión» ${ }^{112}$.

En tercer lugar, podríamos identificar la identidad constitucional europea examinando la jurisprudencia del TJUE, en tanto que este concepto es llamado a ser desarrollado por este, como garante e intérprete supremo del ordenamiento (si se me permite, constitucional) europeo. Si consideramos la mayoría de los hitos jurisprudenciales del juez europeo, podemos concluir que precisamente lo que hace que la UE sea tan peculiar son sus principios de autonomía, primacía (Costa ENEL) y efecto directo (Van Gend En Loos) teniendo la efectividad de la normativa europea como argumento final a favor de su aplicación preferencial ${ }^{113}$; $y$, en este sentido, se han considerado «pilares» distintivos a la par que fundamentales del ordenamiento de la Unión Europea ${ }^{114}$.

Intentar identificar la identidad constitucional, sea nacional, sea de la Unión Europea, ofrece, a una comunidad política, la oportunidad de reflexionar sobre su tradición constitucional, en general, y sobre el núcleo duro de lo que la hace diferente, lo que une a los que la componen, y por tanto, lo que constituye: «the core of its transgenerational constitutional project (...) (accomplishing) a function of constitutional self-understanding» ${ }^{115}$. Rosenfeld, por ejemplo, define la identidad constitucional europea como aquella basada en los elementos existentes de la identidad colectiva europea (lo que, por otro lado, Faraguna ha acuñado recientemente como «constitutional identity despite difference» ${ }^{116}$ ), orientada hacia el futuro y condicionada a la voluntad y capacidad de generar una práctica y cultura europea distintiva ${ }^{117}$. Sin duda, esta definición genérica ofrece la posibi-

${ }^{112}$ JIMENA QUESADA. L., y TAJADURA TEJADA, J.: «La prehistoria y la historia del derecho constitucional europeo...op. cit., pp. 32-33.

113 Asunto C/106/77, STJUE de 9 de marzo de 1978, apartados 18 y 22-23: «el hecho de reconocer eficacia jurídica a los actos legislativos nacionales que invaden el ámbito en el que se ejerce el poder legislativo de la Comunidad, o que de otro modo sean incompatibles con las disposiciones del Derecho comunitario, equivaldría de hecho a negar, por ello, el carácter efectivo de los compromisos incondicional e irrevocablemente asumidos por los Estados miembros, en virtud del Tratado, y pondría así en peligro los propios fundamentos de la Comunidad (...) que, por consiguiente, serían incompatibles con las exigencias inherentes a la propia naturaleza del Derecho comunitario toda disposición de un ordenamiento jurídico nacional o cualesquiera prácticas, legislativas, administrativas o judiciales, que tuviesen por efecto disminuir la eficacia del Derecho comunitario por el hecho de negar al Juez competente para aplicar éste la facultad de hacer, en el momento mismo de dicha aplicación, cuanto sea necesario para descartar las disposiciones legales nacionales que, en su caso, constituyan un obstáculo a la plena eficacia de las normas comunitarias (...) que así sucedería, en la hipótesis de un conflicto entre una disposición de Derecho comunitario y una ley nacional».

114 FARAGUNA, P.: «Constitutional Identity in the EU -A Shield or a Sword...op. cit. p. 1624.

115 BELOV, M.: «The Functions of Constitutional Identity...op. cit., p. 92.

116 FARAGUNA, P.: «Constitutional Identity in the EU -A Shield or a Sword...op. cit. pp. $1625-$ 1626, haciendo alusión a que todas los órdenes constitucionales de los Estados miembros de la UE consideran y hacen especial hincapié sobre la democracia, el Estado de derecho, la separación de poderes, la protección de los derechos fundamentales, entre otros, lo que demuestra una herencia europea común, y por tanto, una posible identidad constitucional europea.

117 ROSENFELD, M: «Constitutional Identity», en ROSENFELD, M., y SAJO, A., (eds.) The Oxford Handbook of Comparative Constitutional Law, Oxford University Press, Oxford, 2012, p. 772. 
lidad de ir concretando la identidad constitucional europea sobre la base de esas aspiraciones, valores y elementos comunes, generalmente llamados «tradicionales constitucionales comunes». Si examinamos la "constitutional identity as difference»" examinaríamos aquellos elementos distintivos del ordenamiento supranacional sui generis, en general, y de la Constitución europea material, en particular, como elementos constitutivos de su identidad constitucional (que propongo sean, entre otros, los principios peculiares que rigen la relación entre los ordenamientos nacionales y el europeo —autonomía, primacía, efecto directo-, las singularidades de su marco institución y decisorio con fuerzas motrices supranacionales - Parlamento Europeo y Comisión-e intergubernamentales — los Consejos-). Y, podríamos entonces, también incluir aquellos principios básicos, no vistos en otros ordenamientos, que gozan de especial protección o distinción como pueden ser precisamente la unidad en el pluralismo o la diversidad con la que se asocia a la UE (recogida también en el art. 2 TUE), el respeto de las identidades nacionales (art. 4.2 TUE) y el respeto a las tradicionales constitucionales comunes de los Estados miembros (art. 6.3 TUE).

La difícil búsqueda de atisbar una definición comprensiva para un ordenamiento que sigue todavía a la búsqueda de su propia identidad encuentra respaldo en los métodos de identificación propuestos, y en tal dirección, estimo que una combinación de los modelos supracitados resulta útil a efectos de definir la identidad constitucional europea; al menos para hacerla más operativa. Corresponde, pues, hablar de la protección de los derechos fundamentales y la dignidad humana, del respeto de la libertad, la democracia, del cumplimiento de la igualdad efectiva y del Estado de Derecho, a la vez que de las relaciones peculiares entre los ordenamientos nacionales y el europeo y los principios que las articulan, y de la existencia y funcionamiento de sus órganos políticos y jurisdiccionales únicos en el continente como parte de la identidad constitucional europea.

\section{CONSIDERACIONES FINALES SOBRE IDENTIDADES CONSTITUCIONALES DIVERGENTES: DIÁLOGO JUDICIAL CONSTRUCTIVO COMO PREVALENTE SOLUCIÓN A LA TENSIÓN DIALÉCTICA ENTRE PRIMACÍA EUROPEA VERSUS RESPETO DE LAS IDENTIDADES NACIONALES}

En la Unión Europea estamos presenciando una realidad en la que cada vez más tribunales constitucionales nacionales han desafiado abiertamente la primacía del Derecho de la UE y la autoridad del Tribunal de Justicia de la $U^{119}$, invocando, a través del artículo 4.2 TUE, su identidad nacional para justificar el incumplimiento de normas,

118 FARAGUNA, P.: «Constitutional Identity in the EU -A Shield or a Sword...op. cit. p. 1625.

119 HALMAI, G.: «Abuse of Constitutional Identity. The Hungarian Constitutional Court on Interpretation of Article E(2) of the Fundamental Law», Review of Central and East European Law, Vol. 43, n. $^{\circ} 1$, pp. $23-42$. 
principios y derechos consagrados en la $\mathrm{UE}^{120}$. Frente a esta resistencia constitucional nacional (sea el uso de la identidad constitucional como escudo constructivo o advertencia, y, en ciertos casos, como misil) por parte de los órganos constitucionales nacionales, la respuesta y solución más pragmáticas, en nuestra humilde opinión, es un diálogo judicial continuo y activo. Tanto el derecho constitucional nacional como el derecho de la UE, y sus intérpretes judiciales supremos, respectivamente, deberían tener en cuenta sus ordenamientos e identidades constitucionales, sobre todo, tomando en consideración la situación jurídica excepcional de la UE y el pluralismo constitucional y judicial presente en la misma. En este sentido, como ha intentado ilustrar el presente trabajo, parece que la primacía del Derecho de la UE, parte de la identidad constitucional europea, ha dejado de ser un principio incondicional, siendo finamente esculpido a base de pronunciamientos jurisprudenciales del TJUE cuando este tenga que examinar, ya no únicamente las tradiciones constitucionales comunes, sino también las identidades constitucionales nacionales, entendidas como las estructuras constitucionales fundamentales propias de cada ordenamiento constitucional nacional, fácilmente identificables a través de los mecanismos propuestos, como criterios de interpretación de dicho principio y límites a la efectiva aplicación del Derecho de la UE.

Si la UE constituye un orden jurídico autónomo, los conceptos, categorías e instituciones que emanan del mismo pueden tener, y de hecho tienen, un significado jurídico propio, autónomo y diferente del de las normas, conceptos y categorías nacionales. Por lo tanto, el Derecho de la UE debe interpretarse a la luz del ordenamiento jurídico europeo, y en consecuencia, las identidades nacionales (constitucionales) de los Estados miembros, cuyo respeto se consagra en los tratados constitutivos de la UE, deben análogamente interpretarse a la luz de los mismos. Sin embargo, el Derecho de la UE también constituye un ordenamiento jurídico interrelacionado e interconectado con el de los Estados miembros europeos: el Derecho de la UE y las legislaciones nacionales son un conjunto de normas, que aunque distintas, se encuentran asimismo estrechamente entrelazadas por el propio funcionamiento tan particular de dicha organización supranacional y la relación y aplicación de las normas que emanan de ella y las de sus Estados miembros. Cada sistema jurídico ha aprendido y debe seguir aprendiendo del otro, y deben continuar en esa tarea de conocerse y aceptarse mutuamente, lo cual es sólo posible participando en un diálogo significativo: como proceso reflexivo, asimétrico y evolutivo ${ }^{121}$ y como crítica constructiva, razonamiento constitucional comparado y con disposición al cambio ${ }^{122}$. En este sentido el art. 4.2 TEU puede entenderse como una oportunidad de apertura para ese intercam-

120 Por ello, se les ha catalogado como «actores clave» en los «enfrentamientos constitucionales de gran repercusión» relativos a «los arreglos supranacionales de la Unión Europea»: WALKER, N.: «Constitutionalism and Pluralism in Global Context», en AVBELJ, M., y KOMÁREK, J. (Eds.) Constitutional Pluralism in the European Union and Beyond, Hart Publishing, Oxford, 2012, p. 21.

121 BELOV, M.: «The Functions of Constitutional Identity...op. cit., p. 86.

122 TADEUSZ-KONCEWICZ, T.: «Constitutional Identity in the European Legal Space and the Comity of Circumspect Constitutional Courts», Gdanskie Studia Prawnicze, n. ${ }^{\circ}$ XXXIII, 2015, pp. 198-199. 
bio entre el Derecho de la UE y el Derecho Constitucional de los Estados miembros a través de sus correspondientes y competentes órganos jurisdiccionales, haciendo al ordenamiento europeo más receptivo al Derecho Constitucional nacional, avanzando un poco más en el proceso de constitucionalización de la UE: «to enhance the constitutional dimension of the $E U_{\gg}{ }^{123}$. Con todo lo dicho, entendemos la tesis de Millet al intentar tender un puente entre el enfoque de la primacía absoluta de la UE y enfoques más pluralistas. A su juicio, la identidad constitucional actúa simultáneamente como norma de resistencia y como norma de convergencia, o en otras palabras, como una única herramienta que acomete dos estrategias separadas pero interdependientes en tanto en cuanto la UE recurre a la «identidad nacional» para acomodar intereses constitucionales sin poner en duda la primacía del Derecho de la UE y los tribunales constitucionales la declaran para justificar su rechazo de la misma ${ }^{124}$.

El principio de primacía nunca se pretendió entender en términos de superioridad o supremacía de un ordenamiento jurídico (el europeo) sobre otro (el nacional). Un cambio de perspectiva es necesario, dejando de pensar bajo el prisma nacional en la noción tradicional de jerarquía cuando se trata de la relación entre el ordenamiento jurídico europeo y los de sus Estados miembros. La noción de jerarquía es provechosa en el ámbito interno, pero el sistema supranacional europeo, como sistema pluralista y multinivel, hace ya tiempo que la superó, buscando ya desde sus orígenes formas de coexistir y cooperar, no anulándose entre sí sino más bien adaptándose mutuamente a las particularidades del otro, con el fin último de garantizar la dignidad humana, la paz y el bienestar de las personas en el territorio europeo. Por ello, Millet califica la identidad (constitucional) nacional como un «principio estructural del Derecho de la UE» que ofrece una vía de mantenimiento simultáneo de la «unidad relativa» y de la «diversidad relativa» en la UE ${ }^{125}$. Así, como elocuentemente lo resume Tadeusz-Koncewicz, "el constitucionalismo europeo no debe ser visto como el enemigo del constitucionalismo nacional, sino más bien como su socio constructivo y crítico» ${ }^{126}$ o como su «interlocutor principal» ${ }^{127}$.

En este sentido, cuando se trata de casos que plantean cierto conflicto entre el Derecho de la UE y la identidad constitucional nacional, los tribunales constitucionales nacionales tienen todo un elenco de elecciones, entre las que cabe repudiar el flagrante desprecio del cumplimiento del Derecho de la UE, y se debe destacar y fomentar la interpretación y aplicación de las normas constitucionales conforme con el Derecho de la UE y, en caso de duda con la compatibilidad de esta con elementos inherentes a su identidad constitucional nacional, remitir la correspondiente cuestión prejudicial ante el TJUE para que califique y/o modifique la jurisprudencia existente en casos legítimos y cardinales de invocación de la identidad constitucional nacional. Así pues, se espera que los tribunales constitucionales nacionales demuestren un

123 BELOV, M.: «The Functions of Constitutional Identity...op. cit., p. 94.

124 MILLET, F.X.: L'Union européenne et l'identité constitutionnelle..op. cit., pp. 188 y ss.

125 MILLET, F.X.: L'Union européenne et l'identité constitutionnelle..op. cit., p. 286.

126 TADEUSZ-KONCEWICZ, T.: «Constitutional Identity in the European Legal Space... op. cit., p. 213.

127 ROMBOLI, S.: «"Los contra-límites en serio” y el caso Taricco...op. cit., p. 22 
cierto autocontrol y minimicen conflictos mediante enfoques interpretativos convergentes que promuevan un diálogo constructivo, evitando las «guerras entre jueces» ${ }^{128}$, moviéndonos del ajedrez (juego que astutamente utiliza Romboli ${ }^{129}$ ) hacia, tal vez algo más en la línea del cubo de Rubik. Estimamos que es necesario rechazar la teoría de los juegos finitos, cuyo propósito es que uno de los jugadores gane, mediante intentos constantes de desafío y hostilidad, y apostar más bien por un juego, si bien con destino incierto, pero cuyo propósito es seguir jugando, intentando encajar todas las piezas, aparentemente en choque, hasta que casen, lo que permite aprender del otro y mejorar uno mismo. Se trata de una búsqueda constante, con espíritu cooperativo y conciliador para encontrar la mejor ponderación de aquellos valores e intereses tan distintos y contrapuestos, con el objetivo de precisar y perfilar las identidades invocadas para avanzar hacia una unión más político-constitucional.

El TJUE no puede definir el significado último ni el sentido único de la identidad constitucional, pues, por un lado, es un concepto «fronterizo» entre el Derecho de la UE y el Derecho Constitucional nacional, y por otro, resulta servir como «recurso instrumental adicional» para modular la aplicación de la primacía del Derecho europeo $^{130}$. En efecto, no le corresponde al TJUE decidir, en solitario, qué constituye la identidad constitucional de un Estado miembro, sino de desarrollar el concepto, a través de su jurisprudencia, como resultado de un diálogo judicial impulsado por el procedimiento de la cuestión prejudicial, a través del cual los tribunales constitucionales nacionales justifican, sustancialmente, el núcleo básico y esencial de sus ordenamientos constitucionales, y correlativamente el TJUE realiza las pruebas jurídicas necesarias, con base en el Derecho de la UE, para admitir, sea en su totalidad, sea en parte o con moderación, las alegaciones de los máximos intérpretes nacionales ${ }^{131}$. Esta

128 CLAES, M.: The National Courts' Mandate in the European Constitution, Hart Publishing, Oxford, 2006; y CLAES, M., DE VISSER, M., POPELIER, P., y VAN DE HEYNING, C.: Constitutional Conversations in Europe-Ius Commune Europaeum, Vol. 107, Intersentia, Cambridge, 2012.

129 Aludiendo a «movimientos de caballo» con la máxima expansión de los derechos y «enroques hacia atrás» por la reafirmación por el TJUE de su propia jurisprudencia». Véase en este sentido ROMBOLI, S.: «"Los contra-límites en serio” y el caso Taricco...op. cit., p. 25.

130 En este sentido, véase BESSELINK, L. F.M.: «National and constitutional identity...op. cit., p. 46 y BALAGUER CALLEJÓN, F.: «The Dialectic relation between national and the European constitutional identity in the framework of European Constitutional Law», UNIO EU Law Journal, Vol 3, n. ${ }^{\circ} 1-3,2017$, p. 20.

131 Para un análisis exhaustivo de cuestiones relativas a los métodos de determinación y competencia judicial sobre la noción de identidad constitucional en el marco de la integración europea, véase CLOOTS, E.: National Identity in EU Law, Oxford Studies in European Law, Oxford, 2015; y sobre cuestiones relativas a la apertura del TJUE a las identidades constitucionales de sus Estados miembros, véase POPELIER, P.: «Europe Clauses» and Constitutional Strategies in the Face of Multi-Level Governance», Maastricht journal of European and comparative law (The Constitutional Adulthood of Multi-Level Governance), Vol. 21, n. ${ }^{\circ}$ 2, 2014, p. 314: "This counter-limits jurisprudence has compelled the EU to intensi$f y$ the protection of fundamental rights at the EU level, and to accommodate national identity narratives in its own legal system. On the basis of Article 4(2) TEU the CJEU has a mandate to deviate from the uniform application of EU law, taking into account a Member State's claim that its national identity is at stake». 
es la interdependencia reforzada en la que se mueve la integración europea, incluida aquella en clave dialéctica ${ }^{132}$. En palabras de Claes, también contraria a una interpretación extensiva, en clave pluralista, de un control constitucional de identidad nacional, el artículo 4.2 TUE, y su interpretación por parte del TJUE, es la única vía de apertura a la negociación judicial para evitar la obstrucción a la aplicación efectiva del Derecho de la UE ${ }^{133}$.

La integración constitucional de Europa se ha realizado tradicionalmente y sigue realizándose, en gran parte, a través de esa transjudicial communication ${ }^{134}$, o en otras palabras, a través del intercambio continuo, directo e institucionalizado entre los ordenamientos constitucionales (por medio de sus máximos intérpretes) y el ordenamiento europeo (por medio del TJUE) en el contexto de la aplicación e interpretación del Derecho de la UE a través del tan relevante e imprescindible procedimiento prejudicial. Por ello, de las tres estrategias constitucionales que propone Popelier (a saber, las estrategias «habilitantes», «impactantes»y «a tres niveles» ${ }^{135}$ ) nos quedamos con su acertada reflexión sobre la inexistencia de una única estrategia idónea pues esta dependerá enormemente del contexto nacional. Por todo ello, abogamos por una «adaptación» o «ajuste» mutuo de los ordenamientos jurídicos en juego. ${ }^{136}$. En esa búsqueda de un punto intermedio, debemos recordar que la doctrina de los contralímites, aunque tenga que ser una concesión indispensable para garantizar un nivel de confianza dialéctica ${ }^{137}$, no puede conllevar a un «exceso de constricciones jurídicas que inhiban la acción e integración europea» ${ }^{138}$.

En otras palabras, la invocación de la identidad constitucional como freno a la aplicación del Derecho de la UE no puede convertirse en un obstáculo estructural continuo, sino que debe utilizarse en casos excepcionales como elocuentemente concluye Popelier: "Al ser causantes de trabas [ciertamente a la integración europeo, en general y a la aplicación efectiva y uniforme del Derecho de la UE], únicamente se debería utilizar

132 MILLET, F.X.: L'Union européenne et l'identité constitutionnelle..op. cit., p. 308.

133 CLAES, M.: «National Identity: Trump card or up for negotiation?» en SAIZ ARNAIZ, A., y ALCOBERRO ILIVINA, C. (eds) National Constitutional Identity and European Integration, Intersentia-Law and Cosmopolitan Values, Cambridge, Vol. 4, 2013 pp. 109-139.

134 SLAUGHTER, A.M.: «A Typology of Transjudicial Communication», University of Richmond Law Review, Vol. 9, n. ${ }^{\circ}$ 1, 1994, pp. 99-137.

135 POPELIER, P.: «Europe Clauses» and Constitutional Strategies in the Face of Multi-Level Governance...op. cit., p. 302.

136 POPELIER, P.: «Europe Clauses» and Constitutional Strategies in the Face of Multi-Level Governance...op. cit., p. 318: «cada estado debería adoptar la estrategia que mejor se adapte a su orden [constitucional], sobre la base de consideraciones sobre (1) tradiciones y sentimientos nacionales, (2) nivel de interdependencia y legitimidad de desafiar [el derecho aplicable], y (3) aspiraciones [suponemos que dialécticas] hacia una coexistencia pacífica» (traducción propia).

137 CLAES, M.: «Constitutionalizing Europe at its Source...op.cit, p. 115: la doctrina de los contralímites como «el precio a pagar por la aceptación leal de la normativa europea en la gran mayoría de los casos».

138 CRAIG, P.: «The European Union Act 2011: locks, limits and legality», Common Market Law Review, Vol. 48, n. ${ }^{\circ}$ 6, 2011, pp. 1942-1944. 
[la doctrina de los contralímites] en situaciones excepcionales o en momentos constitucionales fundamentales como podría ser al avanzar en el proceso de integración con un nuevo tratado de reforma. Dicho de otra manera: el pluralismo impone tanto a los ordenamientos nacionales como al europeo la obligación de adaptación mutua, lo que a su vez requiere cierta "tolerancia constitucional». Un requisito mínimo es la aceptación de otras formas de legitimidad, adaptadas a las características propias de este sistema multinivel» (traducción propia) ${ }^{139}$.

Sin embargo, por un lado, siguiendo con el símil de los juegos y permitiéndome hacer de abogado del diablo, también es cierto, como apunta Balaguer Callejón, que si la identidad constitucional, como la expresión más alta y la esencia distintiva de un orden constitucional nacional y sus estructuras fundamentales, puede discutirse y llegar a hacerse concesiones con esta, ¿hasta qué punto estamos hablando de elementos constitucionales esenciales y fundamentales? ${ }^{140}$. Por otro lado, se ha cuestionado la conveniencia de que el TJUE desarrolle una normativa diferente para cada uno de los Estados miembros en función de los contralímites existentes en cada uno de esos veintiocho ordenamientos constitucionales; aunque también es cierto que ese es el terreno pluralista en el que nos movemos dentro de la UE. Y, de manera más genérica, también cabe poner en duda la conveniencia de dejar que los tribunales constitucionales tengan un papel tan importante en la determinación de la identidad constitucional (y, mutatis mutandis, al TJUE en la determinación de la primacía europea), sobre todo si tomamos en consideración que finalmente los tribunales supremos nacionales (lo mismo que el tribunal supremo europeo) se erigen en mecanismos de defensa ordinaria de la Constitución (nacional y europea, respectivamente).

Desde esta perspectiva, no sería impertinente, en casos excepcionales que se encaucen formalmente, o equivalgan materialmente, a una reforma constitucional a escala nacional o europea, se proceda a la consulta de la ciudadanía europea, pues recuérdese que la reforma constitucional se considera como un mecanismo de defensa extraordinaria de la Constitución. Por tal motivo, ya algunos autores propusieron que, especialmente en casos de reformas de los Tratados constitutivos, sería pertinente el establecimiento del instituto del «referéndum europeo» ${ }^{141}$, es decir, la consulta simultánea en todos los países de la Unión, y no solamente en aquellos en los que sus respectivos ordenamientos constitucionales prevean el referéndum nacional para

139 POPELIER, P.: «Europe Clauses» and Constitutional Strategies in the Face of Multi-Level Governance...op. cit., pp. 318.

140 BALAGUER CALLEJÓN, F.: «Los tribunales constitucionales en el proceso de integración... op. cit., p. 365: «Si los contralímites, en cuanto expresión de una identidad constitucional que merezca ser definida como tal, responden a principios estructurales esenciales al ordenamiento nacional, no parece muy posible que vayan a ser lesionados por una Unión Europea que pretende basarse en las tradiciones constitucionales comunes a los Estados miembros. Es evidente, por lo demás, que los contralímites no son una manifestación del dialogo entre las jurisdicciones sino del miedo de una parte, la constitucional interna, que pretende marcar barreras infranqueables no susceptibles, por ello mismo, de ser objeto de dialogo. Si sobre los contralímites se puede dialogar y ceder, entonces es que no son principios estructurales esenciales».

141 Véase las distintas contribuciones en la obra colectiva de AUER, A., y FLAUSS, J.F. (Coords.): Le référendum européen, Bruylant, Bruxelles, 1997. 
cuestiones europeas esenciales, pues ello provoca asimetrías entre los Estados miembros difícilmente explicables a sus nacionales.

Y por último, nos vemos obligados a preguntarnos ¿Es la identidad constitucional de los Estados miembros, como palmaria contradicción con el Derecho de la UE, reconocido por este mismo, y como potencial límite a la integración europea, realmente la solución y la vía de desarrollo del proyecto de constitutionalización europeo, o será más bien el fruto del árbol envenenado, y por ende, la semilla de una futura ruptura del sistema jurídico europeo y de la integración tal como lo conocemos? Como ya acertadamente concluía Cruz Villalón: «cada uno de los órdenes jurisdiccionales "está en su papel", los tribunales constitucionales utilizando el potencial "esencialista" de la identidad constitucional, y el TJUE proponiendo una versión "domesticada" " aunque "estrechamente vigilada por los Tribunales Constitucionales de los Estados miembros» ${ }^{142}$.

En fin, lo mismo que sucede con la mayoría de los conflictos y cuestiones que se suscitan en el ámbito jurídico, y especialmente cuanto los actores (UE y Estados miembros) pertenecen a la misma familia o al mismo club en cuanto a valores comunes compartidos, la clave radica en la comunicación y en hallar un punto intermedio, al menos hasta la siguiente contienda jurídica. Ahora bien, a la hora de efectuar la ponderación, como acaba de evocarse, si los vasos comunicantes vendrán corrientemente articulados a través del diálogo judicial al máximo nivel (TJUE y tribunales constitucionales o supremos nacionales), en los supuestos más conflictivos (en los que entre en juego la tensión dialéctica entre primacía europea e identidades constitucionales), seguramente la solución insoslayable pasará por recabar la opinión del demos europeo, ya indirectamente a través de sus representantes, ya directamente a través de un referéndum (a escala nacional y, preferiblemente en el futuro, a nivel europeo).

Title:

In the pursuit of constitutional identity: a closer look at the Spanish and European cases vis-à-vis constitutional pluralism and judicial dialogue.

\section{Summary:}

I. Preliminary remarks and conceptual clarity: the nature of the EU and the notion of «constitutional identity» in the context of European integration; 1.1. EU nature, European integration and judicial challenges, 1.2. Constitutional identity as an undefined concept; II. Methods of

${ }^{142}$ CRUZ VILLALÓN, P.: «La identidad constitucional de los Estados...op. cit. p. 514. 
identifying constitutional identity and its materialization in Spain; 2.1. Constitutional preambles, 2.2. Hierarchy of constitutional provisions, 2.3. Unamendability clauses, 2.4. Membership requirements, 2.5. Constitutional interpretation; III. The «national identity of the Member States» in the light of the legal-jurisprudential arrangements and its role in the application of EU Law primacy; 3.1. Materialization of constitutional identity at the EU level, 3.2. The evolution of constitutional identity as a counterlimit to the primacy of EU Law; IV. Alternative approach to a potential European constitutional identity: beyond the «common constitutional traditions»; V. Final considerations vis-à-vis deviating constitutional identities: constructive judicial dialogue as the prevailing solution to the dialectic tension between European primacy vs. the respect of constitutional identities.

\title{
Resumen:
}

En los últimos años, la noción de «identidad constitucional» se ha convertido en un recurso político-constitucional popular a la vez que en un concepto jurídico indeterminado. Resulta difícil tratar de definir la noción enigmática de «identidad constitucional» y su ámbito de aplicación, debido a la falta de consenso entre la doctrina académica, por lo que el presente artículo trata de proporcionar una definición amplia o integradora a través de una serie criterios e instrumentos para su identificación y aproximación jurídica. Con tal premisa, se efectúa un análisis de lo que constituye tanto la identidad constitucional nacional como europea, con especial interés en la identidad constitucional española y la de la Unión Europea. Además, el presente estudio trata de abordar los retos para la integración europea como resultado del conflicto inherente entre la primacía del Derecho de la Unión Europea y el contralímite que consagra en su artículo 4.2 TUE sobre el respeto a la identidad nacional de los Estados que la componen. Finalmente, la autora concluye con unas propuestas de mejora y acercamiento a los problemas planteados, a través de un dialogo activo, constructivo y continuado, impulsado por el procedimiento prejudicial europeo.

\begin{abstract}
:
In recent years, the notion of «constitutional identity» has become a popular political-constitutional resort as well as an indeterminate legal concept. It is difficult to try to define the enigmatic notion of «constitutional identity» and its scope of application. In view of the difficulties in arriving at a precise definition of constitutional identity and the absence of consensus among Academia, this article tries to provide a comprehensive definition through a series legal mechanisms for its identification and legal approximation. With this premise, the author analyses what constitutes national identity, in general, and attempts to define the Spanish and the European Union constitutional identity, in particular. In addition,
\end{abstract}


the present paper attempts to address the challenges facing European integration as a result of the inherent conflict between the primacy of European Union Law and the counter-limit clause, enshrined in Article 4.2 TEU, relating to the obligation to respect its Member States» national identities. Finally, the author concludes with some self-reflections on the approach taken and proposes an active, constructive and continuous dialogue, driven by the European preliminary ruling procedure as a necessary and effective solution.

\section{Palabras clave:}

identidad constitucional; pluralismo; integración europea; cláusula de identidad nacional; teoría de los contralímites; diálogo judicial; TJUE; tribunales constitucionales.

\section{Key words:}

constitutional identity; pluralism; European integration; national identity clause; counterlimits doctrine; judicial dialogue; CJEU; constitutional courts. 